\title{
Tracing social capital within a firm: A relational Capital perspective
}

\author{
by \\ Behrooz Talle
}

A thesis submitted to the Faculty of Graduate and Postdoctoral
Affairs in partial fulfillment of the requirements for the degree of

Master of Applied Science

in

Technology Innovation Management

Carleton University

Ottawa, Ontario

C) 2013, Behrooz Talle 


\begin{abstract}
This study analyzes the effects of relationship capital (RC) on the growth of firms. Social capital (SC) scholars suggest that a firm's relationships drives its growth strategies, but extant literature on SC fails to explain how relational aspect of SC leads to growth of a firm. Built on the resource based theory of the firm and knowledge of SC, this research defines RC as improved capabilities of the firm in combining various resources, and tests whether the existence of $\mathrm{RC}$ in the relationships of a firm affects its growth strategy performance. The results from 347 European firms suggest that relational perspective of SC improves firms' capability to achieve growth and plays a positive role in small firms' competitiveness. The study also opens up some research avenues for an investigation of the effects of trust and commitment, as the two constructs of RC, on a firm's capabilities.
\end{abstract}




\section{Acknowledgements}

Finally, I would like to thank all the people who helped me to reach this page of the thesis! This dissertation is definitely a tribute to my mom who has recently passed away.

I would like to take the opportunity, first of all, to express my best gratitude to my boss and thesis advisor Prof. Mika Westerlund for accepting me as a student in his tight schedule and suggesting various options on which this thesis in based on. I thank him for his patience and constant support during my development of this thesis and am very grateful to him for his helpful and critical comments in writing up scientific papers. His critical comments and insightful feedbacks were essential for the success of all my tasks. It was a great pleasure for me to be part of his initial professorship and supervisory experiences in Canada and to be working in such an excellent constructive environment.

I would also like to express my deepest appreciation to my family especially my father to whom I owe a lot for all of his unwavering supports; he continually and convincingly conveyed the spirit of perseverance in regards to intellectualism and an excitement in regards to pursuing my studies to the highest level. Without his guidance and persistent help I wouldn't be able to achieve this dissertation.

\section{Behrooz Talle}

Summer 2013 


\section{Table of Contents}

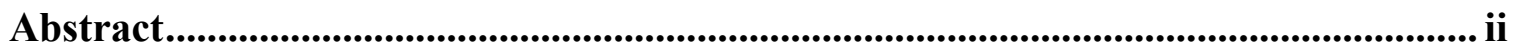

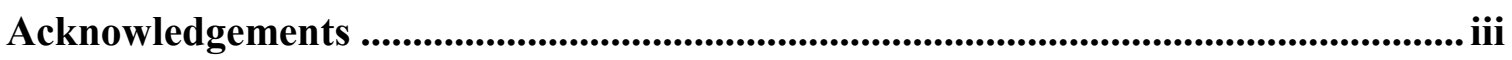

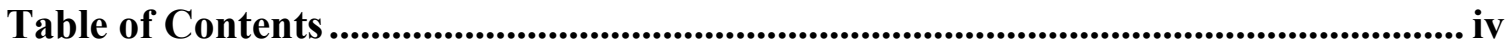

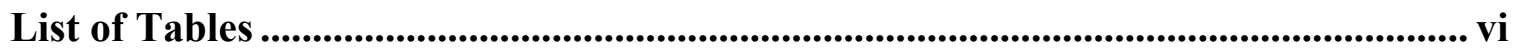

List of Figures................................................................................................................ vii

List of Appendices ............................................................................................ viii

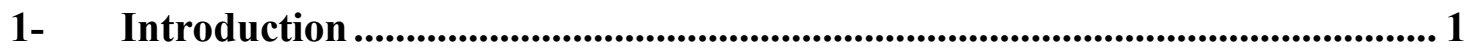

$1.1 \quad$ Research objectives and expected outcomes ............................................... 2

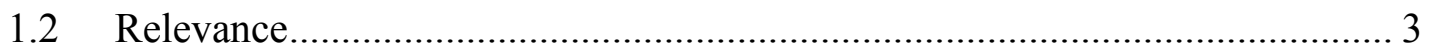

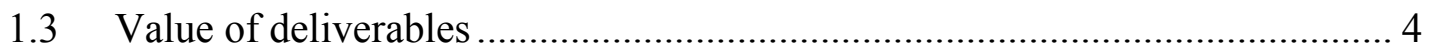

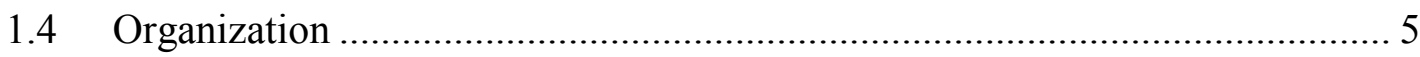

2- Literature Review............................................................................... 6

2.1 Resource-based theory of the firm........................................................... 7

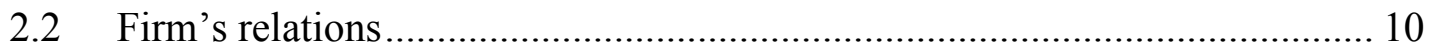

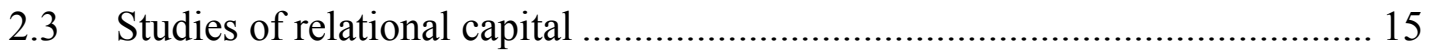

2.4 Firm's concept with regards to relations ............................................... 19

2.5 Growth of the firms ............................................................................ 24

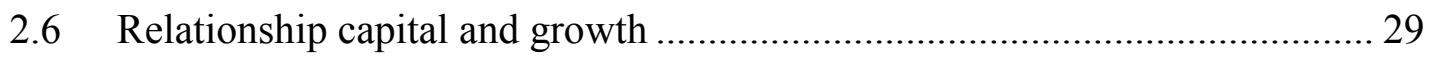

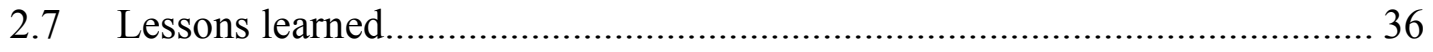

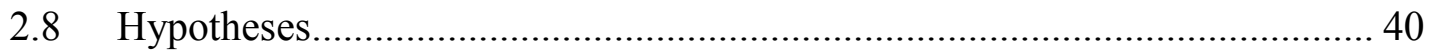

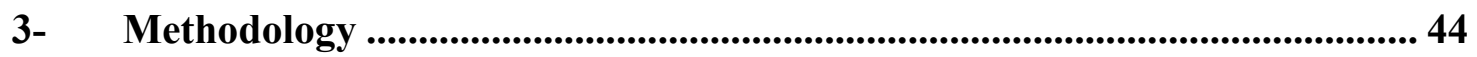

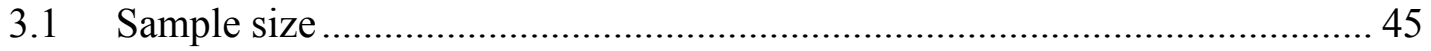




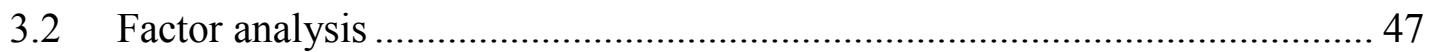

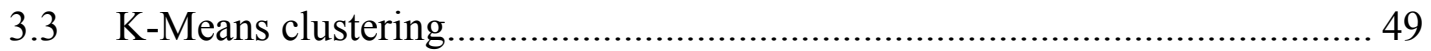

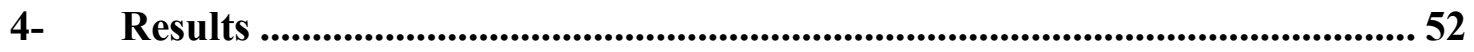

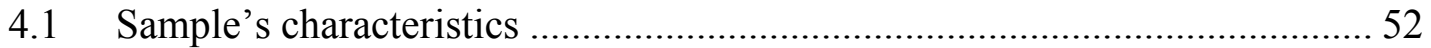

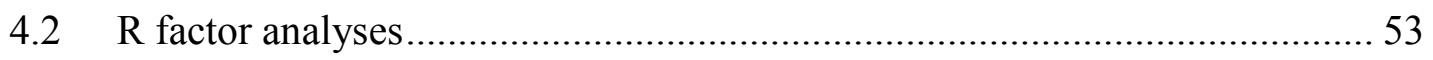

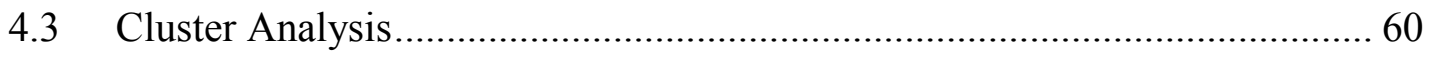

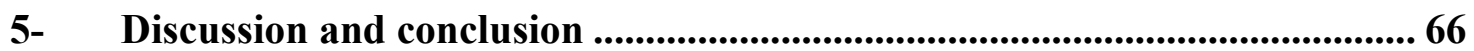

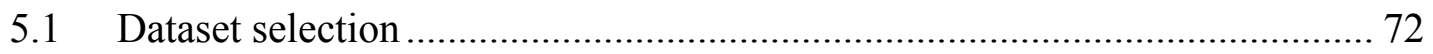

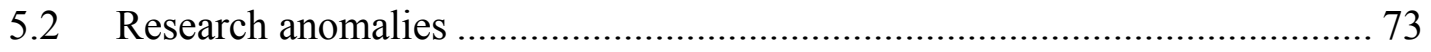

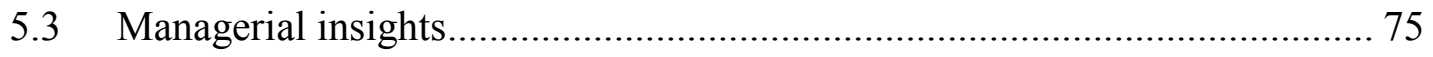

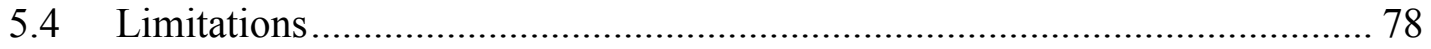

5.5 Future research avenues.................................................................. 78

Appendices..................................................................................................................................... 81

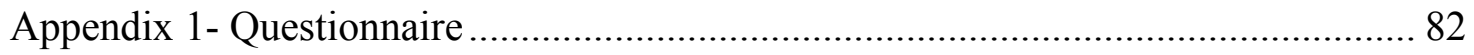

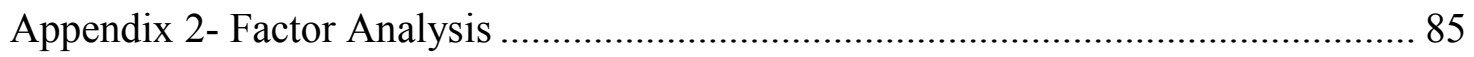

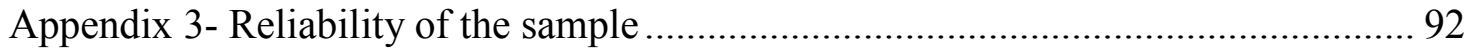

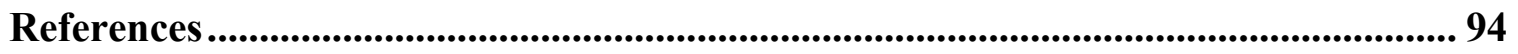




\section{List of Tables}

Table 1- A firm's growth-relationship - Research constructs and findings .................... 32

Table 2- General relationship research categories .................................................... 38

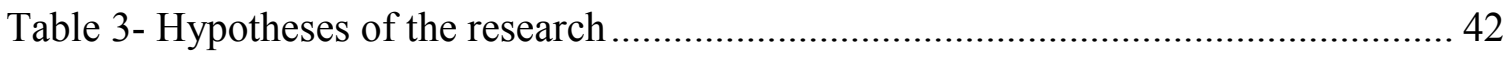

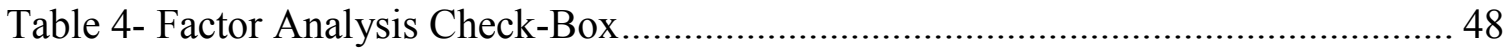

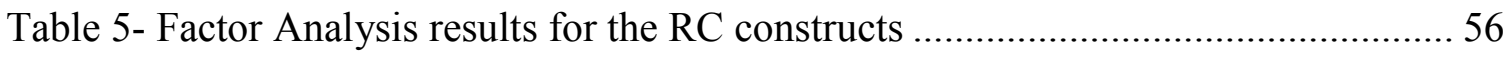

Table 6-Factor Analysis results for Growth Strategy Constructs .................................. 58

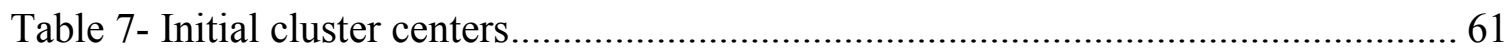

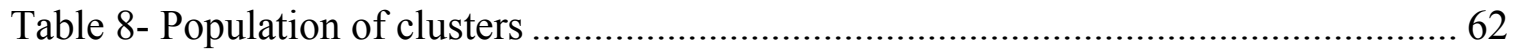

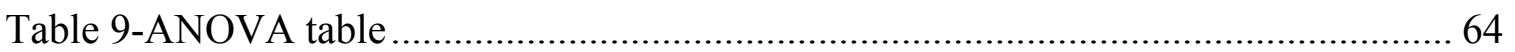

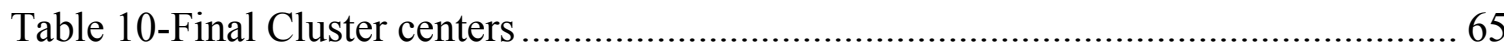

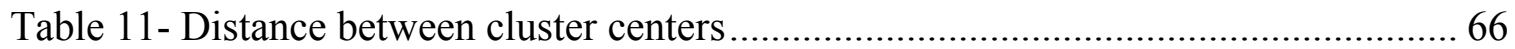

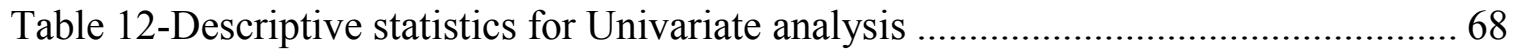

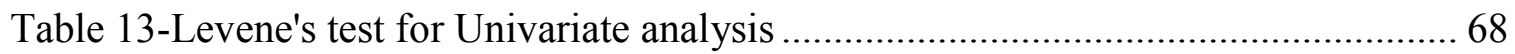

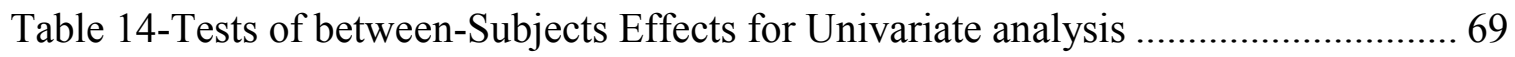

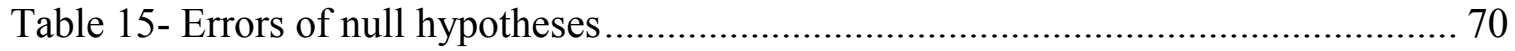




\section{List of Figures}

Figure 1- Relations Grid by Adler and Kwon (2002) (Aspects-Benefit-Risk)................ 23

Figure 2- A conceptual model of relationship capital-firm's growth strategy link......... 40

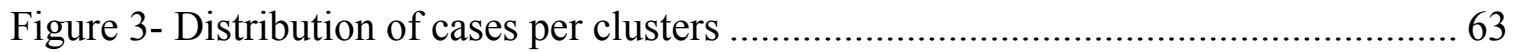




\section{List of Appendices}

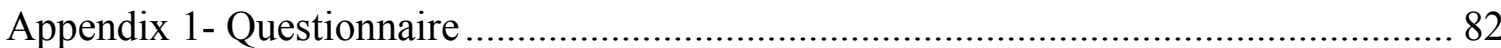

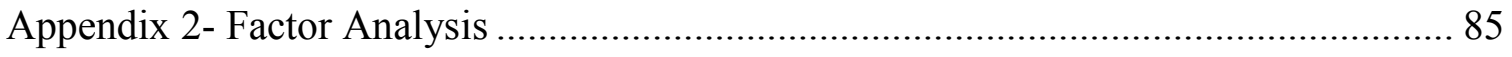

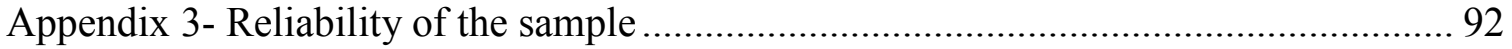




\section{1- Introduction}

The availability of resources at any region across the world at the price comparable to other regions has pushed industry entry barriers low enough for firms with scarce resources to no longer feel secure. This has shifted firms' focus from possessing resources and undergoing costs for acquiring and maintaining those resources by themselves to starting relationships with partners in order to share and use common resources. In addition to the lower overhead costs associated with maintaining of the resources, the relations of a firm's partners and access to their resources bring other benefits such as using the partners' information on market demand and customer preferences. Research on social capital and its effects on a firm's performance have gained importance after the recent economic downturn.

Previous studies show that firms can enjoy economical, behavioural, and social benefits incurred from their relationships to differentiate themselves from competitors. Relationships of a firm are called social capital (SC) and account for all the relationships that a firm has, for example, those that employees have with the community, intimacy of managers of the firm with their peers in the industry, and firm's relationships with partners. As a result, firms may be placed in a position in industry that is unique to itself and which would not be possible if it had not established a relationship (Structural aspect of SC). Or similarly, a firm may gain supports of others upon sharing views about an issue or having common goals with others (Cognitive aspect of SC). 
Eventually, a firm's social capital may be looked as trusted relationships with other firms that bring long term supports (Relational aspect of SC). Put simply, relationship capital (RC) denotes to the benefits that are conducive to trusted relationships of the firms and are long lasting in terms of their impacts on a firm's growth, which will be discussed in this research. Nonetheless, previous studies of social capital lack suggestions on how to imply their results to help the firms lead in competition. A demonstration of the effects of $\mathrm{RC}$ on the resources of the firm would be helpful in this regards. Thus, this study examines RC's impacts on improving firms' capability to achieving growth.

\subsection{Research objectives and expected outcomes}

The purpose of the study is to examine if RC in firms' relationships is associated with the accomplishment of growth strategy. For that purpose, this research analyzes whether or not firms with relationship capital in their partner relationships can achieve their growth. The results will show the association that exists between achieving growth and efforts on building trusted relationships. As few studies have dealt with the performance of growth strategies undertaken by firms from the perspective of partner relations, this research focuses on the link between three steps of successful growth strategy (cf. Baghai, Coley \& White 1999) and the ensued benefits from relational capital of a firm.

The outcomes of this research include answers to the following research questions:

1- How a firm's relationships with partners affect capability of the firm?

2- Is there a positive correlation between a firm's RC and the performance of its growth strategy? 
The deliverables of this study are:

1- A new definition for relationship capital drawn from the resource-based perspective of the firm.

2- Proof for the relationship that exists between a firm's relationship value and the growth of the firm

3- Valuable new propositions for further research in the field of relationship capital.

\subsection{Relevance}

The results of this empirical study are of interest to the academia as the study builds on the assumptions found in the extant literature on social capital's effects on small firms' growth. In fact, the constructs of relational capital research based on the transactional view and the social exchange theory have remained incomplete without having an inseparable third view, the resource-based view. From the academic perspective, the study builds a link between resource-based view of the firm and extant knowledge on growth. Social capital research lacks a perspective from the resource-based view of the firm, and the study is relevant in helping researchers to understand the link between relational capital and resource-based growth strategies.

The significance of results of this research is twofold to small business owners and organizations working with them. Firstly, it adds the significance of partnership factor for formulating growth strategies, adding importance of keeping relationships for lowering the failure rate of small businesses. This study is useful for the entrepreneurs in their search for new partners, as well as in retaining and managing the existing 
relationships for new businesses and new fields. Secondly, the vulnerability of small businesses to even minor failures in their business operations adds to the importance of results of this empirical study. This suggests that the realization and application of RC would be a more cautious practice for small business growth.

\subsection{Value of deliverables}

The results of this study are sources of valuable information for researchers, entrepreneurs, business managers and investors; however the more tangible benefits include:

1- The specific definition of RC was the author's endeavor to establish a clear image of capital term that is used to symbolizing the benefits of relationships of a firm. The value of the new definition is for its simplicity that reduces misinterpretation of terms and results in SC literature which happens in consultations with the managerial literature that deals with the notion of SC.

2- $\quad$ The new definition with the help of findings from this research reduces ambiguities associated with the use of the word $\mathrm{RC}$ for entrepreneurs and business stakeholders. Entrepreneurs can simply use the definition and results of this research to draw their business stakeholders' attention to their RC in explaining nuts and bolts of a business model which is based on relationship with partners and using their knowledge and resources in establishing revenues. 
3- The last but not least value of deliverables of this research is the increase in the awareness of investors about the RC usages. They are able to know the areas that RC should be applied to increase a firm's capability to attaining growth although RC is established in the business models that are presented to them for funding.

\subsection{Organization}

The organization of this study is as follows: Chapter two will discuss the literature on supplier relationship's effects to the firms through the lenses of transaction costs, social exchange, and resource based theory. The growth strategies of the firm and a summary of previous research will also be presented. Moreover, a new definition for relational capital will be proposed for the purpose of facilitating research interpretations, and key research hypotheses are formulated. Chapter three will introduce the research methodology and its suitability for this research. It demonstrates how factor analysis suits the context of this research and what the positive aspects of non-hierarchical clustering technique for this type of research are. The results of the analysis are presented in Chapter four. Chapter five discusses the implications of the results and concludes by explaining the limitations of the study and suggesting some avenues for future research. 


\section{2- Literature Review}

This chapter presents a review of literature on resource based theory of the firm. It shows the dimensions of research that are necessary to investigate the effects of the resources of a firm from its competitive advantage perspective. The two dimensions that are presented will give ground for discussing how changes in the resources affect a firm's capability to implement a successful growth strategy. Previous studies discuss the resources either from the perspective of "isolating effects of the resources in product markets" or "signaling devices in strategic factor market" in order to evaluate the effects of change in a resource on the firm's performance. Looking through an isolated lens, a firm's resources have unique applications for the available range of products, thus, affecting its competitiveness. On the other hand, the imitability of resources and the capability of others to achieve the same quality of resources within a market are discussed from the strategic market factor perspective.

The next section is a summary of literature on social capital and relational capital. This section introduces key streams of research in the study of social capital, and discusses how the knowledge of social capital for firms has developed in parallel with the understanding of the growth of a firm. The section puts forward that the shared cognition of goals with others, placing in different roles in networks, as well as building trusted relationships are the 3 dimensions of social capital.

In addition, the chapter discusses studies related to the growth strategies of the firm, and introduces the steps towards the successful growth strategy. Elaborating the growth 
strategies helps understanding the relationships that are going to be analyzed for relationship capital of the firms and growth strategies. Finally, the chapter puts forward lessons learned from the literature and explains how this research can benefit from those lessons. Those lessons helped developing research methodologies as well as formulating research hypothesis for research which is explained on the final section of this chapter.

\subsection{Resource-based theory of the firm}

Firms' competitive advantage in this research denotes the availability of certain resources in hand or an organization's capability to use them. A firm's competitive advantage, when looked from the perspective of the resource-based view of the firm, is the function of access to or possession of resources with certain qualities. In fact, resource-based characterizes competitive advantage of a firm through explaining its resource characteristics, factor market conditions which states for what reason firm's resources are not imitable and organizational ability to perform well in a market (Leiblein, 2011).

According to Barney (1991), a firm's resources include all assets, capabilities, organizational processes, firm attributes, information, and knowledge. This broad and complete list clearly identifies the arenas that a firm can invest to use the relationship at the moment or in future. Barney (1991) views a firm's resources as:

1. Physical capital: physical technology, firm's plant and equipment, geographic location. 
2. Human capital: training, experience, judgment, intelligence, relationships, and insight of individuals.

3. Organizational capital: reporting structure, planning, controlling and coordinating systems, and informal relations within a firm and environment.

The three attributes of firm's strategic competitive advantage are worth outlining here because they add to understanding of how these resources turn into competitive advantage. The three attributes are isolating value of a resource, factor market conditions, and organizational abilities.

\subsubsection{Isolating value of a resource}

Value of resources is investigated in an insulated manner in response to the question on how the resources of a firm enable firms to design and apply various strategies to control, access, or organize productive resources in a way that improves firms' efficiency and effectiveness (Barney 1991). The competency of firms from this perspective can be measured through (1) technical fitness to productivity or quality-to-cost ratio, and (2) dynamic capability factor that is a firm's enablement via having scarce resource in market place (Leiblein, 2011)

\subsubsection{Factor market conditions}

The ability of the resources to provide competitive advantage for a firm is explained through the factor market perspective which stresses the imperfection of resource imitability (Leiblein, 2011). As discussed by Barney (1991), the imperfection of imitability is a critical point in the competitiveness of resources. It implies that resources are unique at: 
a) Their history: once the time passes, firms with no time dependent resources may lose the chance of having resources like organizational experience in an emerging market.

b) The ambiguousness: the causal link between possessing resources and the competitive advantage is blurred. This causes that the firm and its competitors fail to grasp the functionality of the value added activities.

c) Social complexity of resource: Social processes through which a firm's resources that are the base of a firm's competitiveness are the hardest to imitate. Interpersonal relationships and reputation are examples of these resources. (Barney, 1991)

\subsubsection{Organizational abilities}

The organizational abilities view explains that firms differ from each other in terms of performance. This is because of the organizational capabilities they have (Leiblein, 2011). From this perspective, the dynamic capabilities of resources are explained through:

1- Manager's experiences: firms are gifted if they ran by the managers with diverse background and experiences. In this way, the market ups and downs or difficulties would be less affecting the performances.

2- Business structure of organizations: firms that are structured flexibly are well performed in the tolerance of markets. Market fluctuations need the changes in 
business practices that are commonly not tolerated by organizations that are shaped firmly and can't incorporate the change within themselves.

3- Benefits of their well-known organizational processes (cognition). This denotes to the processes within a firm to which employees and personnel have adapted, and to the inputs of organizations in this process to make the value added products.

In sum, the resources of an organization are heterogeneous (Barney, 1991). The three discussed approaches indicate that from each perspective a resource of the firm has qualification that separates it from other resources. Leiblein (2011) agrees with Barney's (1991) heterogeneity aspect of resources for each of these qualities, and suggests that research from capability based method perspective needs to consider economic contribution of resources “...through their influence on value and cost drivers, market position, or isolating mechanisms" (Leiblein, 2011).

\subsection{Firm's relations}

The networked industries of today, as defined by Ritter, Wilkinson, and Johnston (2003), enforce firms in markets to increasingly compete for gaining an edge against the competitors. Indeed, a firm can exist if it has competitive advantage over others, and that is ensued by the reciprocal exchange of benefits with other firms (Ritter et al. 2003). In addition, establishing relations is the only way to achieve efficiency for the existing firms, meaning that all firms should be connected to have the opportunity to access more resources so that they can survive (Nyaga, Whipple, \& Lynch, 2010; Teece, 2000). 
Firm's resources can be tangible for which there are no acquisition costs. Alternatively, they can be intangible like firsthand information from the market and customers that gives a firm a relative competitive advantage of mixing the scarce resources in a productive way (Leiblein, 2011). The word "relative" here means that the inefficient market, in which new information can play the crucial role to escalate the firm's productivity, is not a static status quo but it is changing all the time.

The relative productivity also refers to the profit-cost trade-off upon which the productivity is measured. Given the importance of having new solutions or products for a firm to enter the market, the information gained through the partner's relationships increases the chance of new product development success, and it decreases the costs associated with market exploration (Mu \& Benedetto, 2012). Indeed, the cost of knowledge itself to buy in market is considerably high for the new firms. It is because of the intrinsic association of new information with the people who own it, organizational contexts it belong to, and processing and filtering procedures that take to process the information to be ready to use cost a lot and are sometimes not possible (Teece, 2000).

When it comes to the efficiency, the industry in which all the resources are available at comparable prices all over the world, substantiates better value match to the customer's demands unless the competitors that would make this match can capture the market no matter where they are geographically located. Distribution of resources around the world gives equal access to resources for each firm. However, a firm may suffer low 
productivity ensued by the lack of resources in a sense that the link the firm has had to build - which makes the owners of these competitive prices available to a firm - does not exist. Therefore, the efficiency of that firm as compared to the connected firms drops dramatically (Ritter et al. 2003). This means that the small firm's mistakes - however trivial they are - may turn into a huge failure costing the whole business.

\subsubsection{Social capital}

A firm's relationships are of great importance in facilitating co-creation and exchange of resources (Pulles \& Schiele, 2013). These two activities are performed upon the existence of social capital (SC) for the firm. SC is considered as the ties between firms, individuals and corporate actors that enable them to exchange benefits, resources, and perform mutual activities together (Coleman, 1988). In this study, capital is regarded as finances available to the firm, which are divided into capital from investors and non-investors.

Based on that definition, any benefits that are conducive to relationships are called relationship capital (Burt, 1997). The capital nature of the relationships is now used widely since their connection to the performance of the businesses is taken seriously, and relationship capital is now considered as a major source of competitive advantage (Teece, 2000; Mu \& Benedetto, 2012).

The relationships of a firm are discussed in literature and range from the relationships that employees have with their community that they belong to (Fernandez, Castilla, and Moore, 2000; Westerlund \& Svahn, 2008) - these employees are either managers or 
workers - to organizational relationships between suppliers, buyers, and partners (Hakansson \& Ford, 2002; Adler \& Kwon 2002; Nyaga et al. 2009; Kohtamaki et al. 2013), or the combination of the two (Partanen et al. 2008; Teece, 2000; Mu \& Benedetto, 2012).

Social capital ensures access to all the resources available over the span of market with the same price (Ritter et al. 2003). This is because the characteristics of social capital would let the firms that possess them to have access to the resources. These characteristics, as suggested by Nahapiet and Ghoshal (1998), include:

1- Structural links or social ties between firms (structural capital)

2- Strong relationship built on trust (relational capital)

3- A shared vision and shared interpretations of the relationship (cognitive capital)

The listed characteristics are discussed in the following sections.

\subsubsection{Structural Capital}

Ritter et al. (2003) explain a firm as the combination of internal and external relations. Whether acting collectively with other firms or not, firms are considered as networks of relations and outcome of relations that grows through the evolvement of relations. If the relations were unincorporated, the structural aspect of social capital would just be a name that barely explains the total effects of gathering. It might grow in numbers like a circle

of friends, but not show the volume of effects as incorporated relationships. Therefore, if 
the firm exists as incorporation of relations, it enjoys the benefits of the relations more than its intellectual abilities and other assets (Ritter et al. 2003; Burt, 1997).

\subsubsection{Relational Capital}

The main function of the relational dimension of social capital is to facilitate resource exchanges for actors within the resource environment (Pulles \& Schiele, 2013). For instance, employees of the firm belong to the communities that empower them and their employer organization more than what they are able to do individually (Social capital). The social relations of personnel are believed to be a source of resources that are unknown and never considered prior to the employment time (Teece, 2000).

This hidden asset flourishes and turns into one of the known benefits for the firms. Whereas cited that “...social capital lies in the social structure in which actors are placed" (Adler \& Kwon, 2002; Hakansson \& Ford, 2002), discussions about understanding and using such resources in practice have rarely asserted that relation among firms are capital of the firms or they have the similar values as other resources.

The major indicator of this kind of capital is trusted relations. Trusting channel relationships are shown to induce upstream partners to allocate more resources to selling the suppliers' products, and Firms may better utilize their trusted ties through repeated exchanges when interactions between firms increase (Pulles \& Schiele, 2013). The key to have the trusted relationships is the preferences of parties to keep in touch base with each other without any hesitations. This constant and secure promise to support each other is 
called commitment for which parties make sacrifices (Pulles \& Schiele, 2013). Indeed, the partner ties will not exist if there is no reciprocal exchange of benefits. This asserts that "Trust" amends the "Commitment", and vice versa.

\subsubsection{Cognitive capital}

Organizational contexts are the cause of importance of knowledge in employees' relations. It means that the human resources of the firm as the time passes will gradually gain importance from competitors' perspective. In other words, these resources are valuable owing to their access to the various sources of information, which are only sources of the firm to keep its competitive edge. Their values are compared against the other employees outside the firm who are not having the same skills and information that they possess.

Teece (2000) argues that knowledge trade between organizations only happens when the employees and their environment as well as contexts transit from a company to others. In fact, the knowledge is valuable because this transfer is almost impossible. Access to the information is cumbersome job if there is a mindset that a merger may solve the problem because the new company would never reflect the same conducts and contexts they had before.

\subsection{Studies of relational capital}


Research in relational capital varies in terms of the techniques used and the interpretation of results. Roughly all the studies in this vein use interactions between two sides of the relationships to assess the load of benefits and costs incurred through firms' connections. Such studies are particularly looking for economic, strategic, and behavioral benefits of transactions (Wilson \& Jantrania, 1995). This stream of literature delves into the cost reduction aspect of the businesses engaging in relationships. Hence, the qualitative studies on this vein are showing that managers are in favor of the relations that are lowering the costs. The studies of social capital can be found in three different streams: 1Transaction based perspective (TBV) 2- Social exchange theory (SET) 3- Resource-based view of the firm (RBV)

\subsubsection{Transaction-based perspective}

Mu and Benedetto (2012) make an example of a social capital study from transactionbased perspective that shows the new product performance relates positively to the cost reduction on production and market research level, as well as the lower cost of market penetration. Having the success ratio of new product development as a measure for effectiveness of collaborative approach, $\mathrm{Mu}$ and Benedetto (2012) identified that firms can benefit from the networking at the development stage in three main domains that are: 1) market knowledge, 2) technology knowledge, and 3) interaction cost reduction.

The message implied through Mu and Benedetto's (2012) research is the cost reduction role of the networks of the firms that a firm is in contact with. Access to each piece of knowledge they need for the product development stage, such as how market may react 
to the product or what would be their preference to its range of features, cost a lot more in terms of time and money. Whilst the network that is knowledgeable of market demands and expectations save the firms costs of redoing the market test and knowledge access, and eventually increases the success in product development.

\subsubsection{Social exchange theory}

Discussion about the network industries and existence of dyadic relations (a single relationship within a network that has 2 parties involved and one thread that connects them) embedded in complex networks of relationships are something that social exchange theory traces back into. Interpretation of networks according to node and thread approach is a common method for assessing the abilities and deficiencies of a network. Relations as threads in a network schema of nodes and threads would need constant investments to be alive and the more the relations bear load of exchanges the heavier and riskier that thread and node is (Hakansson \& Ford, 2003).

Hakansson and Ford (2003) have investigated the theory of social exchange to show how the bonds and bridges would affect the opportunity discovery and market expansion of the firms. Their study - which shows how the relationship between people in a network of professionals may benefit the affiliates of a specific person - considers the close ties between a person and others as bonds. Within the bonds the people know each other very well, and this improves the level of intimacy every time they contact each other. Thus, bonds that have been made based on the trust between the two people would let the flow of information to have less friction and increase the commitment to relationships. 
On the other hand, bridge connections are defined in each network as the connections that a specific person has with the far from reach and not well-known person who is a part of another network of ties. Hakansson and Ford (2003) argue that the newness of knowledge and the immediacy of access to them have more value than the bonds. Although the commitment and trust among the close ties increases the performance of operations, the first-handedness of information through bridges leverages the network a lot more than what the continuous improvement of performance in that network of bonds does.

In other words, the relative competency of each network is defined by the number of bridges they have. In Hakansson and Ford's (2003) research, bridge is a link or the connecting thread with investments placed on them that abridges the route of flowing information via couple of intermediary(s) and directly connects the parties of interest to each other. These bridges are the fruits of exchanges of common interest and benefits between two nodes as explained in detail by Hakansson and Ford (2003).

The value of the discussed view to this study is that a node with the highest capital is the one that connects a variety of close and distant nodes through a system of threads and keeps this trade-off balanced. Establishment of links and the development of nodes and threads depend on the respective investments; the bridges that each node has from outside into the firm (Achrol, 1997; Hogan \& Armstrong, 2001; Hakansson \& Ford, 2002).

\subsubsection{Resource based theory}


The third category of constructs for research has its basis on the resource-based view of the firm, which investigates the changes happening to the firm through domesticating other partner's activities and resources. Trading these assets is almost impossible, but their effects on the business performance is staggering (Teece, 2000). The capital produced in this way is the source of competitive advantage for the firm and resourcebased view of the firm accredits time dependent resources as competitive advantage of firms (Barney, 1991). For example, Hogan's (2001) notable study investigates the effects of resources created by a firm on manufacturing processes efficiency.

Resource-based approach is seeking the methods for managing relations and identifying how firms can generate high level of profits (Hogan \& Armstrong, 2001). For instance, Hogan (2001) identifies value centers in which firms' relationship can be helpful for the improvement of manufacturing process. Hogan's (2001) research has pointed two specific areas improving the time of delivery and reducing manufacturing costs. Although the return on the investment relates to both receptivity of the firms and value of information gained from relations, both depend on the level of investments or total resources (Ulaga \& Eggert, 2005).

\subsection{Firm's concept with regards to relations}

Managing the businesses has changed during years because the rate of inefficiency time in the market has dropped drastically, and because imitation of resources as the way of keeping the edge over the competitors is not a hurdle for competitors anymore. So the competition is now changing to the local arenas in a sense that each region demonstrates 
the niche markets with its own customization and demands of products. Therefore, the competitive advantage fades soon and the importance of ways to make the unique solutions to markets in an efficient manner increases.

Leiblein (2011) asserts that competitive advantage is a firm's performance through application of resources, which is achievable through:

- $\quad$ sustainable market position (higher value capture position)

- superior economic contribution (value creation)

The traditional view of capability management encourages incorporation of partner's skills into organizational systems to attain a competitive advantage (Badaracco, 1991). It implies that the wise choice of managing relationships was to merge the business operations with new partners to incorporate their skills and knowledge source into firms. This idea fails to make sense anymore because the value captured through this mechanism, considering costs of acquiring resources and incorporation of new skills into the status quos, is not high and in today's business world because neglecting a competitive price factor for market offers is favorable for competitors to gain an edge over other businesses by just offering lower prices.

The narrow line between success and failure caused by the distributed and well-spread market does not allow implication of the time and cost efficient approaches that were common for adding competitive advantage previously. Badaracco (1991) cites the acceptable value-adding approach was to improve the productivity inside the companies, 
and get bigger and more efficient through adopting changes from outside. In fact, the isolated approach to resources was more demonstrated on the traditional management skills.

As the competitive advantage approach asserts, the strategies for business improvements from this view are not reliant on value of the businesses in a factor market conditions (Leiblein, 2011) or individualistic approach (Teece, 2000). In other words, factor market condition looks at firms' capabilities from the market point of view and in order to find possibility to find a replica for them in market whereas individualistic approach considers the sources of value and capabilities of firms in terms of monetary values.

However, the competitive advantage of firms is valuable as long as it is continuously applied in the areas that business model has defined. Therefore, there is no possibility for buying or selling the sources of competitive advantage unless Badaracco's (1991) recommendations for merging the firms applies to reality or the firm's relationship with partners and resources of competitive advantages be strong enough to use them as if they are part of the firm's business models.

Relationships with value chain members have to be treated as they are vital parts of business models adding an opportunity to increase the value added to the customers, keeping them satisfied yet loyal to the firm's ecosystem for a longer period of time (Daum, 2006). A simple product with open options to complement and tailor the product into customized solutions works the best. This way, value added management would keep 
the adding-value part outside the company to lower the cost of administration changes while giving the known solutions as value adders which are adaptable to the firm's product (Daum, 2006).

The capital (relationships) built in this way make the source of competitive advantage for the firm, and the resource-based view of firm accredits time dependent resources as competitive advantage of firms (Barney, 1991). While the invested assets on the relationship building phase are almost impossible to trade, their effects on the business performance are staggering and difficult to imitate (Teece, 2000). From the management point of view, the measurement tools or techniques are the key for managing the operations.

Achrol (1999) cites the managerial implications for being in network industry as the lower overhead for those companies acting together. Tackling production problems is another incentive for managers (Achrol, 1999; Hogan 2001) which is now considered as a source of competitive advantage to firms (Hogan, 2001), producing knowledge assets that are hardly copied and are specified to those producers (Teece, 2000).

Managing a new firm comprising relationships is a challenging task to do. The balance between the sacrifices and benefits is a sole managerial issue on collaboration and relationships between partners (Adler \& Kwon, 2002). Figure 1- Relations Grid by Adler and Kwon (2002) (Aspects-Benefit-Risk) illustrates three key relationship benefits: opportunities, ability, and motivation. They are the product of information, influence, and 
solidarity, respectively, and bring both risks and opportunities to the firm. The reason for depicting them as a portion of semicircle in the figure is to show that they are influential but not the whole prerequisites for competitive edge against competitors.

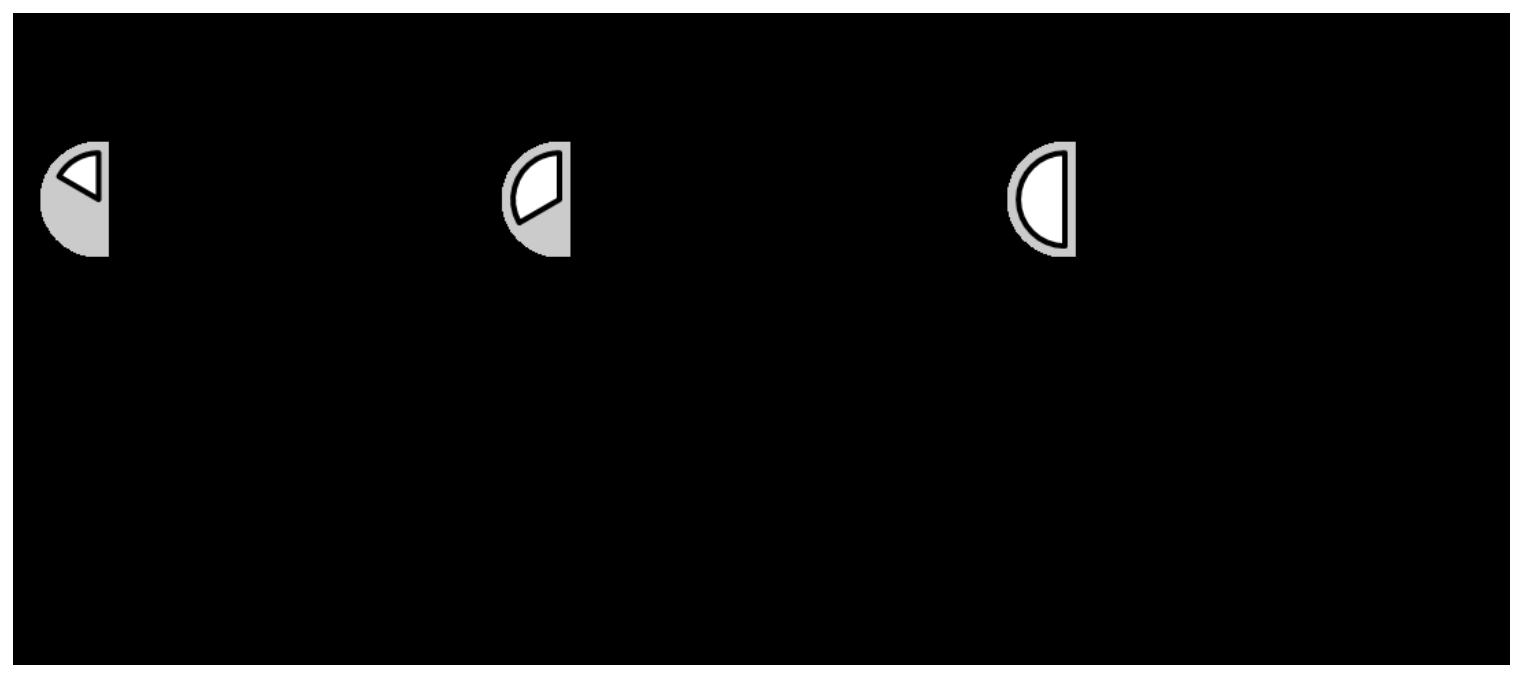

Figure 1- Relations Grid by Adler and Kwon (2002) (Aspects-Benefit-Risk)

The first set of risk-benefits on the left side argues that the opportunity available information can offer also costs for developing relationships. Opting for increase in investments to an opportunity, a firm is overloaded with preparing and exploiting options for that opportunity so that developing a project by itself takes more time. The middle set, ability and its risk factors, implies that the party that possesses the information from the last stage can seize the ability and influence on the others to direct the development towards its own stakes. Moreover, the natural reaction of the opposite party to this movement is to mingle more with other parties and encourage them to involve in the network, which moves some nodes into isolation. 
The last set in trade-off is the motivation and solidarity. This means that the opportunity seekers are limited to not benefit as much as they can and to leave the others to perform proportionately, because it evolves future opportunities more than what the available networks have. The figure draws attention to the network, and management of it implies the fact that connections among the firms are not providing the almighty. Indeed, the combination of firms and connections that are well invested enable the firms do more than before but with some limitations.

In sum, this section discussed many changes faced by the management of the firms. It specially assisted us in understanding new dimensions of firm management in networked industries. For instance, from the social exchange theory perspective, relations bring information, power, and control that have to be in balance with the restrictive approaches that impede innovativeness as well as loosening practices that lower the attachment and further evolvement of networks (Hakansson \& Ford, 2002; Hogan, 2001; Adler \& Kwon, 2002)

\subsection{Growth of the firms}

While recent surveys (e.g. http://ic.gc.ca) show the foremost factor that contributes to a firm's growth directly relates to its R\&D activities, research on management of growth strays from this fact. R\&D expenditures promote two functionalities of a firm. One of them is the creation of new businesses with the help of the novelty of their outcomes. Exploring the demands for a breakthrough technology and convincing the market to a better solution that the R\&D outcomes propose are examples of new business creation. 
The other implication for $\mathrm{R} \& \mathrm{D}$ expenditure is the generation of new revenue model for the existing business. This approach helps the businesses expand their operations and adds more revenue by increasing efficiency of a company in its market activities.

Increase in employment, sales volume, exports, and market share are common features of growing firms. However, these factors are considered as the classic methods for the growing companies (Baghai et al. 1999). A company has to expand geographically because the new markets are scattered all around the world. Increase in manager's compensation and improvement on their employment status are dependent on reaching those markets. Consequently, sales volume is the only factor to measure a firm's performance which might be inferred from the export levels or the market share as compared to the competitors. Indeed, classic growth literature summarizes the indicators of growth as follows (Baghai et.al 1999; Curry \& Hodgson, 2008; Anthony, Johnson, \& Sinfield, 2008):

1. New businesses introduction

2. New sources of profit

As practically all the reviewed literature on growth affirms the relationship between knowledge creation and growth, strategic movement towards creation of this factor has remained the same. Anthony et al. (2008) cite the strategic movement to the new market niche as the first step towards growth while the incorporation of feedbacks into the current business concept and moving towards serving different tier of customers selected 
as the second way of growth. An examination of the literature shows the intention of various researchers towards a three-step approach.

The life cycle of a firm has three major levels and implies that it is acceptable to see a new business as the starting point of a company, as well as a new strategic move, when a firm that is at higher stage of a maturity is going to decline. Aligned with the same logic, the new areas for generating revenue from market or new market stage make the strategic approach for companies for growing to maturity level.

Importance of knowledge has been used widely in literatures related to growth. The main feature associated with knowledge is the idea of newness. In literature, whenever the term of knowledge is evident a procedure involves in creating a step-by-step causal model. In general, this process that always associates with uncertainty and risks takes sacrifices to achieve newness (Hogan, 2001). Similar to growth, as mentioned previously in the study, the three different perspectives on studying social capital each have their own history behind telling that the progress happened in the past to create them.

Information has been cited vastly as a source of valuable knowledge for the firms (Teece, 2000; Mu \& Benedetto, 2012; Baghai et al. 1999). However, the knowledge has been illustrated in their studies differently. Teece (2000) cites the information as knowledge in different areas of market and technology. While the information is synonymous to any knowledge of outside boundaries of a firm which later can play important role in the firm's operations to increase their performance, yet the specific definition about 
information depends on the context of each research. Nonetheless, what can be said is that knowledge related to the firm's growth is the filtered information or the information that is not repetitive and can be used instantly for specific operation.

The examples of organic growth and extraordinary growth of firms by Baghai et al. (1999) illustrate that the strategically built relationships of a large and small companies before the time they achieved the growth were the hardcore of those companies. They achieved a phenomenal growth because every piece of knowledge they used and every step that the passed were fit strategically to others.

Hence, growth in this study is defined by two different functions and a three level strategy. Creating a new business and expansion to a new market are two identified functions for growing firms. However, resource scarcity demands for strategic look at these functions. A sound growth plan includes the following three aspects (Baghai et.al 1999; Curry \& Hodgson, 2008):

1. Seeding the ongoing growth options;

2. Testing and extending the new business concepts;

3. Managing the profitability.

As Baghai et al. (1999) emphasize, resource scarcity is like a framework that limits the boundaries. The results of their survey that targets the successful companies as well as the firms that failed on their growth strategy provide a fundamental support for their 
three-tiered growth schema. There is a generalized pattern among the firms that handle the strategies successfully. The successful implementation of growth strategies expected from firms with robust plans for future in which investments on potential opportunities for growth took place previously. The categorization of opportunities to longer and shorter term in potentials allows the continuous growth since the investments and the expectation of returns are in accordance with this strategy. Out of this scope the growth strategies end in failure.

The strategies have been studied extensively (e.g. Curry \& Hodgson, 2008), and new changes towards the stepwise strategic action plans have been repeatedly introduced. For example, Anthony et al.'s (2008) research show new venture's growth, although referenced to the same process, differently:

1. Work closely with first customers and go to market partners;

2. Exploit what is unique to your customers in downturn and in normal times;

3. Improve operating performance.

Although the same three level strategies by Baghai et al. (1999) were implied in Curry and Hodgson's (2008) research, the former has drawn attentions to the marketing performance to attain the growth, as well as supporting the last common point among the three perspectives, which is managing the last step of growth. 
The common denominators in growth literature are identified as a firm's higher performance (Baghai et al. 1999; Curry \& Hodgson, 2008) and managing the ex post situation for leaving positive customer's perception of a grown firm (Anthony et al. 2008; Daum, 2006). The literature also shows the importance of robust strategy for action plans, resource consideration into strategy, and a true strategy for incorporating actions for leaving positive image to customers into other activities relevant to growth, plays a complementary but crucial role on success of growth strategies.

\subsection{Relationship capital and growth}

In this research relationship capital defines clearly as the new capability of a firm. As it understands from capability based view, firms are capable because their resources are unique in the market or their position to access resources outside the boundary of their operations is special (cf. leiblein, 2011). In other words, all that makes firms capable is related to the resources by themselves or the relationships that make them accessible. Relational benefits perspective explains that firm's relations are more important than any other resources because the relations are not replicable or purchasable in the market (cf. Burt, 1997).

In addition to the importance of relationships of a firm, resource based view of a firm grants the value of access to complementary resources in a market to the proximity advantage of firms that are in relationships with other firms in industry (cf. Pulles \& Shiele, 2013). Put simply, firms with few relationships can have the higher proximity value because they strategically connect to the partners with strategic resources. 
Therefore, relationship capital is a wise chose of relationships as well as effective use of resources as the below definition states them clearly:

Relational capital (RC) is the firm's ability to unique assemblage of resources with the help of the process of information sharing with partners that leads to creating more of an interfirm value than of outside market value.

This definition sets well with the results of other researches on the social capital of the firm. For instance, Westerlund and Svahn`s (2008) study suggests that managers attribute the effects of the relationship capital more to the higher level performances and those that lead to the substantial growth of a firm. The value of such a capital is measured through "the proxies". It means that the "trust and commitment" mentioned previously as the determinants for the existence of RC would be measured through performance of the actions that they have resulted.

The cost of knowledge sharing is one of the methods. Mu and Benedetto (2012) have identified the value of collaboration with partners through the proxy of new product development success in terms of market share and acceptance. On the other hand, there is cost of acquiring and processing knowledge which makes sense to be measured through the investments that firms are doing on their market channels (Hogan \& Armstrong, 2001). This means that the firm attains information from its value chain, expanded supply chain to the extent that it covers stakeholders as well as complementors and competitors. 
Hence, relationship capital does not exist before a firm exploits any sort of benefits from a relationship.

Consequently, relational capital grows when the ties between a firm and other partners are found, exploited, and strengthened. This growth is a result of investments and interactions that the firm has with its partners. Aligned with the last section's streams of knowledge developed to investigate social capital, this section provides the impacts of relational capital classified according to the performance and value added (the customer perspective) effects of relationship that firms have. Table 1- A firm's growth-relationship - Research constructs and findings provides a summary of literature that was studied for the purpose of the research.

\begin{tabular}{|l|l|l|l|l|}
\hline Author(s) & $\begin{array}{l}\text { Research } \\
\text { constructs }\end{array}$ & Units of analysis & $\begin{array}{l}\text { Effects found } \\
\text { on performance }\end{array}$ & $\begin{array}{l}\text { Effects found } \\
\text { on customer }\end{array}$ \\
\hline $\begin{array}{l}\text { Nyaga et al. } \\
2009\end{array}$ & $\begin{array}{l}\text { Trust, } \\
\text { Commitment }\end{array}$ & $\begin{array}{l}\text { Exchange } \\
\text { partners }\end{array}$ & $\begin{array}{l}\text { Influence or } \\
\text { restrain a } \\
\text { partner's } \\
\text { actions }\end{array}$ & $\begin{array}{l}\text { Long term } \\
\text { sustainability, } \\
\text { loyalty }\end{array}$ \\
\hline $\begin{array}{l}\text { Hakansson \& } \\
\text { Ford, 2002 }\end{array}$ & $\begin{array}{l}\text { Trust, } \\
\text { Commitment, } \\
\text { Information } \\
\text { sharing }\end{array}$ & $\begin{array}{l}\text { Threads, nodes, } \\
\text { contents }\end{array}$ & $\begin{array}{l}\text { Strength via } \\
\text { investments } \\
\text { and mutual } \\
\text { activities }\end{array}$ & $\begin{array}{l}\text { R\&D and } \\
\text { market } \\
\text { development }\end{array}$ \\
\hline Adler \& Kwon, & $\begin{array}{l}\text { Trust, } \\
\text { Commitment, } \\
\text { Information } \\
\text { sharing }\end{array}$ & $\begin{array}{l}\text { Kartners } \\
\text { Knowledge } \\
\text { nature of } \\
\text { relationships }\end{array}$ & $\begin{array}{l}\text { Social relation } \\
\text { facilitates } \\
\text { processes of } \\
\text { recognition and } \\
\text { flows }\end{array}$ & \\
\hline
\end{tabular}




\begin{tabular}{|c|c|c|c|c|}
\hline $\begin{array}{l}\text { Teece, 2000; } \\
\text { Hakansson \& } \\
\text { Ford, 2002; } \\
\text { Adler \& Kwon } \\
\text { 2002; Mu \& } \\
\text { Benedetto, } 2012\end{array}$ & $\begin{array}{l}\text { Trust, } \\
\text { Commitment, } \\
\text { Information } \\
\text { sharing }\end{array}$ & $\begin{array}{l}\text { Knowledge, } \\
\text { market, \& } \\
\text { technology } \\
\text { partners }\end{array}$ & $\begin{array}{l}\text { Market and } \\
\text { technological } \\
\text { performance } \\
\text { (NPD) }\end{array}$ & $\begin{array}{l}\text { Market } \\
\text { acceptance }\end{array}$ \\
\hline $\begin{array}{l}\text { Partanen Moller, } \\
\text { \& Westerlund, } \\
\text { 2008; Ostrom \& } \\
\text { Ahn, 2007; } \\
\text { Westerlund \& } \\
\text { Svahn, } 2008\end{array}$ & $\begin{array}{l}\text { Cognition, } \\
\text { Trust, } \\
\text { Commitment, }\end{array}$ & $\begin{array}{l}\text { Relationships: } \\
\text { Management } \\
\text { level, Customer } \\
\text { level, Supplier } \\
\text { level }\end{array}$ & $\begin{array}{l}\text { Performance of } \\
\text { R\&D }\end{array}$ & $\begin{array}{l}\text { Directing } \\
\text { activities of the } \\
\text { firm towards } \\
\text { new business }\end{array}$ \\
\hline $\begin{array}{l}\text { Fernandez et al. } \\
2000\end{array}$ & $\begin{array}{l}\text { Trust, } \\
\text { Information } \\
\text { sharing }\end{array}$ & Referrals & $\begin{array}{l}\text { Performance of } \\
\text { recruitment } \\
\text { process }\end{array}$ & $\begin{array}{l}\text { Consistency of } \\
\text { service }\end{array}$ \\
\hline Hogan, 2001 & $\begin{array}{l}\text { Trust, } \\
\text { Commitment }\end{array}$ & $\begin{array}{l}\text { R\&D } \\
\text { Units/investments }\end{array}$ & $\begin{array}{l}\text { Performance of } \\
\text { manufacturing }\end{array}$ & $\begin{array}{l}\text { Consistency in } \\
\text { consumer } \\
\text { satisfaction }\end{array}$ \\
\hline
\end{tabular}

Table 1- A firm's growth-relationship - Research constructs and findings

As Table 1- A firm's growth-relationship - Research constructs and findings shows, the major questions regarding the existence of relational capital are related to trust and commitment between partners. Although information sharing has been cited as a third dimension for measurement of relationship capital, this effect is considered to be very context related for the studies like Fernandez et al. (2000) in which the aim of companies in using social capital was to attain information from employees. In other words, firms that are under study from different perspectives have used the ways that were suitable for their business to build the relationships, in most cases they established mechanisms to 
achieve trust and commitment but in a the information intensive cases they used information sharing medium to start and maintain relationships.

Although highly dependent on the research limitations, these constructs are normally found together in different contexts. Specifically, bonds and bridges are used as the unit of analysis for researches from the social exchange perspective. However, the other two approaches for research (transaction-based and resource-based perspectives) have wider choice for the unit of analysis; all studies that are listed in the table investigate the growth of firms.

Nyaga et al. (2009) studied how firms can achieve business growth while they are committed to the partners in order to provide the complementary solutions to their simple product. Partners trust each other because their fate is tied together. Customers' loyalty is achieved through the trust and commitment among partners because the tailored solutions to their needs always exist in that partnership. Companies are sustainable by delivering simple solutions to market that associates with lower cost of acquiring resources and processing them.

The growth discussed by Fernandez et al. (2000) pointed to the one dealing with internal efficiency of training and recruitment processes. Fernandez et al. (2000) measured trust as information sharing between partners, illustrating the value of social capital within a call center, and indicating the social exchange revelation of employers. The referral process used by the call center employer let them know who has the ability to adapt more 
to the job. This resulted in a lower rate of employee recruitment turnover, which is positive for the company that has the high rate of employees leaving their jobs. Moreover, it reduced the cost of training and more saved resources since the referrals have already been told that the working environment is good for people with certain aptitudes.

Trust and commitment have been used vastly in the literature as two foundational constructs indicating the prevalence of social capital. However, there is discrete use of the two constructs with regards to the perspective and scope. Westerlund and Svahn (2008), Partanen et al. (2008), and Ostrom and Ahn (2007) found them as higher level constructs related to the relational perspective of social capital, and explained that they have effects on a firm's growth. Exchange partners react to each other's operations so that they limit, improve, and distract the performance of firms; however, the long term sustainability and increase in loyalty of partners by these interactions is evident (Nyaga et al. 2009).

Looking at findings from the Industrial Marketing Group's research which focuses on social capital (see e.g., improvement of market performance by Hakansson and Ford (2002), it seems evident that the higher the investments on the mutual activities are the more robust market development and R\&D activities are reported. Furthermore, the more educated the respondents are, the more accurate and detailed the proposed model by the researcher is. As various authors (e.g., Partanen et.al 2008; Ostrom \& Ahn, 2007; Westerlund \& Svahn, 2008) who have developed their research questions around the 
cognition of relational capabilities, as well as around the trust and commitment between the partners conclude, firms are able to direct their activities towards growth opportunities.

Anderson and Jack (2010) assert the trust aspect of the relationship would just be an initiative to start transactions. Moreover, Nyaga et.al's (2009) results show that the mutually beneficial activities are those that both parties involve in and that lead to trust and commitment. These factors will further lead to the improved satisfaction and performance. By the same token, $\mathrm{Mu}$ and Benedetto (2012) investigate the effects of networking ability and discuss what networking consequences on NPD performances are from the social exchange perspective. The results demonstrate close similarity to those firms benefiting from having knowledge assets (Teece, 2000). The following items are indicators of either of performance or satisfaction:

1. Interaction Cost Reduction;

2. Opportunity Discovery;

3. Resource Acquisition;

4. Market Knowledge Generation;

5. Technology Knowledge generation.

$\mathrm{Mu}$ and Benedetto (2012) assert that the new product development performance is also related to the collaborative activities that firms are involved with customers and suppliers. On the other hand, Nyaga et al. (2009) has indicated that the supplier's 
performance depends on mutual activities that it has with a firm, and vice versa. This affects the growth of the firm on keeping the profitable customers loyal while the supplier who is not in forefront of the chain more profitable.

Furthermore, Westerlund and Svahn (2008) found out that the relationship capital demonstrates a pattern in firms' growth. Senior managers, as the respondents of their study, cite the financial performance in accordance to the level of relational aspect of social capital. At the same time, there are some probabilities of occurrences of benefits that lead to the growth of the firms (Ulaga \& Eggert 2005, Hogan 2001, Partanen et al. 2008). Hogan (2001) simulates the uncertainties associate with the reliance on the benefits of the relationships for firms and the results of the analysis show the improvement of processing time and reduction of costs in manufacturing processes which bring growth to manufacturing firms.

\subsection{Lessons learned}

Studies of social capital from the relational perspective would substantiate from a careful look at the usage of the term 'capital'. Whether capital is considered as something to have a return for the firm or as something that builds strategic competitive advantage for the firms, it is the subject of research. As mentioned in previous sections, studies of social capital differ in this point by focusing on the return on transactions or exchange or the competitive advantage attribute that social capital adds to resources. Moreover, capital is internal to the firm so that its relationship to other internal affairs of a firm is necessary. 
In general, capital provides competitive advantage or at least has an effect on the performance of the firm, as resources usually do. Looking at the relational capital and tracing it inside the firm is to give the resource attribute to an external effect. In other words, the relationship of a firm which were external to other resources are now attributed as the internal ability of the firm to check its capability to grow against the state of the firm in which relationship did not exist. As mentioned previously, resource based view to the capability of the firm makes it possible to check the firm's capability at to achieving growth.

In order to analyze the capability of a firm from the strength of its resources perspective, two ways exists. If we analyze the competitiveness of the firm against the average industry rations and measures, we can choose the Industrial Organization model (IO model of strategic competitiveness). The other way, which seems more suitable for this research, is the resource-based view of the firm that starts internally and compounds the strength in resources and capabilities, to strategic plans that are to be applied to the attractive industry. Therefore, this study benefits from the view that deals more to the internal characteristics of the firms, as they are changing under the influence of partner's relations.

The main function of a firm's social capital is to facilitate resource exchanges for actors within the resource environment. However, the relationship capital of the firms accounts for their internal abilities to add value to the resources. The degrees of trust and commitment as two factors of relationship are indicators to which extent the firm that 
develops them in a relationship can estimate its growth; the more trust and commitments are, the more expectations for growth are.

Aligned with the strategies for firms' growth and the steps towards their successful implementation, extant research shows how social capital affects the performance of strategies. As table 2 shows, all the reviewed studies on SC investigate the performance of the firms, although their approaches towards measurement differ from each other.

\begin{tabular}{|l|l|l|}
\hline Theory & Measurement criteria & Relational aspects used \\
\hline Transaction Cost Analysis & Performance-satisfaction & Relational mechanism \\
\hline Social exchange theory & Performance & Trust, Commitment \\
\hline Resource-based theory & Performance & Trust, Commitment \\
\hline
\end{tabular}

Table 2- General relationship research categories

Nyaga et al. (2009) looked at the long term effects of a firm's social capital on customer loyalty and the ensuing sustainability of the firms. Their study shows that firms that have more interaction with partners digest more of the market needs and can be more effective in finding markets for growth. The firms offer complementary products/services to the partner's products/services and have high performance in terms of market reach because they have more loyal customers.

Mu and Benedetto (2012) looked at the improvement of product development stages from the relational point of view. The industry, technology, and market knowledge, as suggested by Teece (2000), affect the success of new product development. In both 
studies (i.e. Teece, 2000 and $\mathrm{Mu} \&$ Benedetto, 2012), trust was associated with the inception of interactions, meaning that the relationships started with the certainty about the help that actors can get from their partners. While commitment needs more long lasting actions from partners to be shown up (Teece, 2000), there was no sequence in relations for trust and commitment and some relations have just shown to be based on the commitment.

Prior studies on social capital show that the optimum number in the relationships should be such that they reach the maximum results for improvements. A smaller number of connections is not associated with the lower chance of improvement. Hakansson and Ford (2001) shows that the broader the span of the manager's relationships (more bridges), the higher the bar of competitiveness for the firm. In this case the managers have less reference to be traced, and the level of competitiveness of the information increases because of higher chance of inimitability.

In sum, prior literature suggests that social capital has effects on a firm's growth. It is understood that ability of firms for growth is derived from the resources that they have In other words, if the firm's social capital affects its resources or capabilities, its growth will be affected. Although SC can enable a firm to achieve its growth, it is long term relationships with partners that change the capability of firms. That capability stems from relational aspect of SC and is called RC because by itself is part of capabilities of the firm. On the other hand, a firm's growth strategy has to be related to what firms do to increase the inimitability of their resources. $\mathrm{RC}$ is inimitable because it is a part of the 
culture and practices of the firm that achieved it. Together these lessons show that RC is granted as abilities of a firm to influence its growth. Figure 2 depicts the conceptual relationships that relational capital has with the growth strategies of a firm.

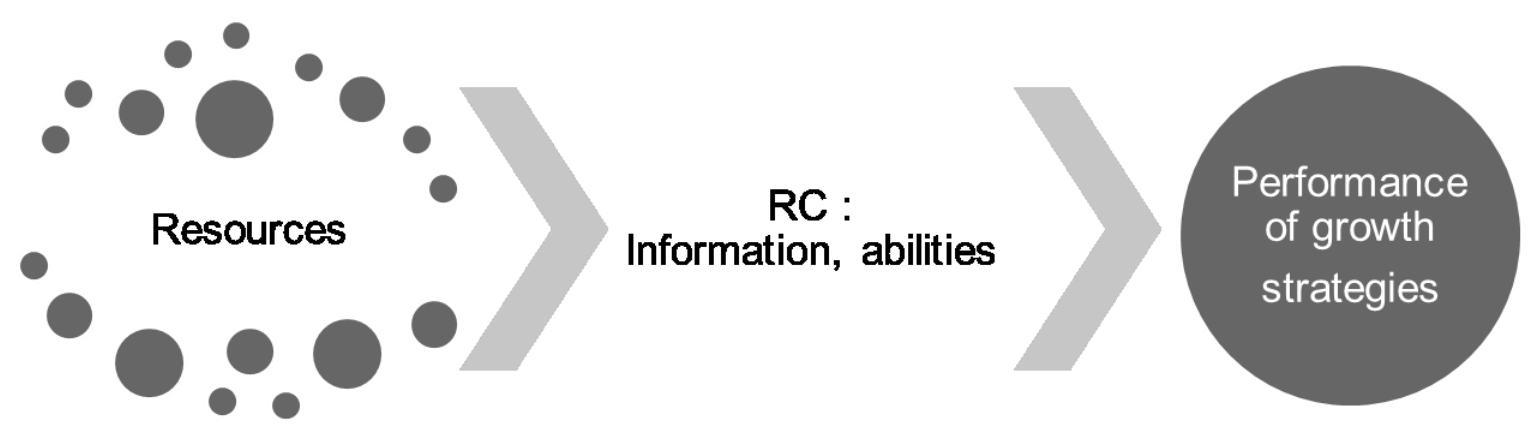

Figure 2- A conceptual model of relationship capital-firm's growth strategy link

This figure shows that the current resources of a firm will transform through the RC which is a combination of information and abilities that the firm gains through relationships with partners. This transformation of resources will impact growth strategies and performance of the firm to implementing the strategies.

\subsection{Hypotheses}

This study investigates the effects of relational dimension of social capital on the performance of a firm's growth strategies. The study includes an analysis of an empirical data that was provided for this research, and the aim will be accomplished by clustering the firms on the dataset to interpret the association of the RC and steps of growth. 
Therefore, this study assumes that relational capital has a direct impact on a firm's abilities that are used for growth strategies.

It is stated during the research that the $\mathrm{RC}$ in a firm directly affects the performance of growth strategies of a firm. Therefore, the null-hypothesis addresses effect on the dataset. The study opts for testing the null hypothesis to provide $t$ and the testing ground for the scenario of the research, which considers how $\mathrm{RC}$ makes changes to the resource structure of firms and helps achieving growth. Though, the null hypothesis states that the presence of RC does not have any effects on firms achieving growth.

As mentioned previously, growth strategies are based on three step "sub strategies". The first strategy step is 'seeding the options. Within the social capital literature, the importance of allocating the resources to R\&D activities and mutual investment of the partners on them show great significance on the growth of the firms. Hakansson and Ford (2002) suggest that optimum effect of relationships be explored in a way that firms avoid having bonds, but rather try to make bridges to have new and filtered information for the options for growth.

For the second step of growth strategies, 'testing new business ideas' and replicating old business models are recognized as the proper action towards growth. Testing the market suggests the crucial changes into deliverables of the firm even if options are checked before (Baghai et al. 1999). As mentioned by Teece (2000), information may be called the greatest assets that firms with outperforming strategies have. Mu and Benedetto's 
(2012) research on knowing the market feedback before introducing the product into market have shed light on this stage.

The third step of growth strategy is the 'management of profitability' of the firm after the replication of old strategies with new ones. This means that firms should be more flexible in terms of the changes that they have to embrace toward implicating real growth strategies. For instance, firms with greater than average growth incorporate necessary changes into the current systems to be ready for embracing new business streams (Baghai et al 1999). Relationship capital has also been shown to improve the manufacturing processes in terms of costs and quality of the outputs (Hogan 2001). The time and cost efficient processes are the major success factors for the systems that Undergo changes and need flexibility for managing aftermath of the changes.

According to the messages that growth strategy literature convey and what the studies of social capital and its relations to growth of the firms demonstrate, the alternative hypothesis for this research puts forward that the presence of relational perspective of social capital in firms relationship will positively affect their growth (see Table 3 ).

\section{Test 1}

$\mathrm{H} 0$ : existence of relational capital in a firm's relations with partners does not have any effect on performance of growth strategies of that firm

Ha: Existence of relational capital in a firm's relations with partners has positive effect on the growth strategy performance

Table 3- Hypotheses of the research 
Contrary to the positive effects, the lack of relations is a point of weakness for the firms (Hakansson \& Ford, 2002). Bonds and bridges catalyze the flow of information from partners to a firm while a firm's strategy for growth will be only accomplished through the access to that information. The lack of major bridge leaves the firm without crucial information which might offer an access to certain resources. In terms of resources, Ritter et al. (2003) mentioned the network industry would impede an isolated firm to perform for long time. This study would complement these approaches toward investigation of relational capital by suggesting the lack of relational capital would be a major hurdle to firms to grow. Errors of analysis set will check for this impact.

Errors of analysis would also suggest if the experiment has flaws in the processes and calculations, meaning it will show if any group of firms exist that does not have $\mathrm{RC}$ and still have growth (Type I error). Or, they show the lack of integrity in results if relationship capital exists while having deficiency in implementing growth strategies (Type II error). Errors of this study will not be sufficient to reject the logics behind the alternative hypothesis of the research; however they can show avenues for further research that are valued deliverables. 


\section{3- Methodology}

Studies on growth strategies of the firm are widely spread in the literature, meaning that each study has its own assumptions of a firm's growth indicators. The present study tests if the relationship capital (RC) increases the capability of firms to achieve growth. However, since analysis for this research takes place on a previously collected data there should be two tests, one for showing each of $\mathrm{RC}$ and growth indicators within a dataset, and another for finding cluster of firms to show effects of RC-Growth.

The dataset on supplier partnerships was collected in 2002 by Helsinki School of Economics and its partners in Europe as a part of an international research project on supplier relationships. The part of survey that used for this research contained two groups of questions that addressed both the nature and current atmosphere of the relationships as well as the realization of expectation from those firms that are in relationships.

Respondents were asked to measure their responses based on a five-point Likert scales from 0 showing that respondents were "completely disagree" with the statement to 7 that means respondents were "strongly agree".

Performing an explorative study, this research starts with factor analysis to indicate the constructs of the discussion, drivers of relationship capital, and growth strategies. For relationship capital the two constructs, "Trust" and "Commitment", and for growth strategies the results are limited to the three factors showing "Seeding the options", "Testing and expanding new business ideas", and "Managing the profitability". 
In order to show the reliability of the research, first the test for the goodness of the method is interpreted. Among those are the Kaiser-Meyer-Olkin (KMO) measure of sampling adequacy tests, and Bartlett's Test of sphericity which tests the level of correlations among variables.

Meanwhile, this research opts for further explorative analysis that would be based on the results of clustering analysis. This method groups the firms (respondents) into categories that are similar from the perspective of dealing with relationships. This method should corroborate the suggestions by Kajalo et al. (2007), who argue that the test should be started with formulating the clustering problem and defining variables for that clustering analysis.

\subsection{Sample size}

The viable number of respondents and sample size has been discussed in the literature extensively. The sample size criteria used for this research comply with the Tabachnick and Fidell (2001) recommendations, according to which the minimum acceptable size is 50 and the "good" number of respondents in a sample is, at minimum, within 200-300 range. The data selected for this research has a sample size of 347 respondents, which is on the range of "good" sample size according to Tabachnick and Fidell (2001). The sample was drawn from two northern European countries, Germany and Finland, addressing the firm's relationships with their suppliers. The selection criteria for using the sample included that it provided the best conceptual and empirical match with this study's focus. 
In two sets of questions used for this research, respondents were asked questions to "Evaluate the current nature/atmosphere of the supplier relationship", and also respond to questions about "Expectations versus realization in the supplier relationship" based on the Likert scaling method (from 0 showing that respondents completely disagreed with the statement to 7 that means respondents strongly agreed with that sentence).

Answers to the questions define variables that are in close visual correlations of suppliers' relationship values (Adler \& Kwon, 2001; Westerlund \& Svahn, 2008; Ulaga \& Eggert, 2005). For this research, the questions at the first set identified as the measurement of trust and commitment solely. The respondents were asked to identify to what extent they trusted their relationships in terms of the information shared the ability and so on. These questions also addressed the commitment of firms to their partners. Sacrifices and investments were two common themes of these questions that also mentioned on the extant literature to identifying the level of commitments (Adler \& Kwon, 2001). Therefore, two main attributes of relational capital were under investigation at this questions set.

In another set of questions, respondents were asked about the realization of their expectations of the benefits in regards to the firm's relations. Questions are closely related to the strategic growth aspects; the ones aforementioned. Teece (2000) emphasizes the role of information sharing at industry, market, and customer preference level on competitive advantage. Baghai et al. (1999) summarized the cases in which the 
unlimited support of the suppliers have been the pivotal strength of the firms to growth; achieving competitive edge by improving process of manufacturing based on the partner's suggestions (Hogan, 2001) and product development based on partner's market experience by Mu and Benedetto (2012) (see Appendix 1 for the related questions).

\subsection{Factor analysis}

Firstly, a factor analysis was used to reduce the data. A total of 347 respondents and 33 questions together on both subjects of the study imply that this choice is a proper one to follow, because the number of observations is much more than the number of variables. As suggested by Stewart (1981), the study used the R method for factor analysis in which the variables are examined against each other to find the communality among them. The step-by-step details of performing the R factor analysis are not explained here (more information on the method can be found through the references), but the analysis was based on the three simple criteria that are characteristics of R (cf. Stewart 1981):

- Factors are loaded by variables not persons and occasions,

- Persons are the indices of associations, and

- Data are collected on one occasion.

An aspect that links these three steps of $R$ analysis together is that in this research the dataset was selected as the representative of the population, so that there is no need to consider factors as individuals and perform a confirmatory analysis to find out the population response rates (see Table 4 for a factor analysis check-box). 
An issue when performing an $\mathrm{R}$ factor analysis is that one has to use the rotations for an explorative analysis. It means that each factor should be replaced at least once while examining other variables against each other to assess which one of them is more frequent. For this reason, the R factor is highly preferable according to Stewart (1981) since, for example, the Q method of factor analysis fails to consider the rotation needed for exploring a factor. As another reason to perform a factor analysis is that dataset used in this research was designed and collected by other researchers, and the treatment for them should be similar to the latent or unobservable variables to find (Devellis, 2012). The $\mathrm{R}$ gives the variance of attributes around each factor; however the factors explored via $\mathrm{Q}$ would give the firm and fixed attributes that different people may show.

\begin{tabular}{|l|l|}
\hline Stewart's (1981) suggestions for CFA results & Dataset characteristics \\
\hline $\begin{array}{l}\text { Kaiser-Meyer-Olkin ratio (Measure of Sampling Adequacy, } \\
\text { MSA) not below 0.5 }\end{array}$ & .762 \\
\hline Bartlett's Test of Sphericity & $\begin{array}{l}1671.421, \text { significant } \\
(.000)\end{array}$ \\
\hline Anti-image correlation and covariance matrix & $\begin{array}{l}\text { Not diagonal at all, but } \\
\text { converges }\end{array}$ \\
\hline $\begin{array}{l}\text { Scree plot of latent roots in a factoring procedure should at } \\
\text { least have one sharp break }\end{array}$ & $\begin{array}{l}\text { Checked and has one sharp } \\
\text { break }\end{array}$ \\
\hline
\end{tabular}

Table 4- Factor Analysis Check-Box

Besides, every researcher is seeking the simplicity on the analyses so that the used method possesses the easiness and others can follow and replicate the analysis. The study uses an iterated principal axis factor with three factors as the method of extraction; a Promax oblique solution as described in the following. Screeplot, Bartlett's sphericity test, and Kaiser-Meyer-Olkin's ratios were chosen for the adequacy check. 
I have selected 2 factors for the set of a_5 questions (Appendix 2- Factor Analysis: see 85). The reasoning for that is twofold: one is the consensus of the literature on two attributes of relationship capital; trust and commitment. As mentioned in the literature review, the two attributes have always been investigated through the social capital studies. Having the questionnaire in mind, the second reason to choose two factors is that there is no question asking for information sharing intentions of respondents clearly. The general comment is that the questions address the level of trust and commitment, and how the respondents reach that level, whether it is by sacrifices throughout the time or it happens spontaneously.

I have selected 3 factors out of a_ 6 questions. Again there were the theory reviews, SPSS pattern table, and scree plot initiatives to help in choosing the three factors. Rotations are chosen as the oblique ones because of the interdependency that usually exists among the trust-commitment issues and the answers to the questions, accordingly.

\subsection{K-Means clustering}

Contrary to hierarchical clustering that determines a distance or similarity matrix between all pairs of cases and needs large number of observations for analysis, k-means clustering analysis was recognized more practical for this explorative research with limited number of respondents and small sample size as compared to thousands that would be needed for hierarchical analysis. 
K-means clustering requires the number of clusters in advance. For that purpose, the SPSS software gives an option to check the clusters' acceptability in terms of number of cases that are allotted to each cluster. The number of observations (cases) for each cluster are sought to be equally distributed in this research. This method allows each case to be assigned to all the other clusters at different iterations to see of the results are match with those clusters or not. In this way, the initial similarity or difference between two clusters does not impede allotting the case to other clusters, the common problem found on hierarchical methods.

Within the cluster analysis, the method chosen for this study was K-means that is assumed to give realistic results owing to its neutral nature of partitioning the data. It partitions the data into the group of cases that are similar to each other according to the variables that are defined beforehand and through the factor analysis. This avoids having subgroups inside each cluster that are basically built in the bases of the similarity among the cases. In fact, the dataset that is available and does not let the researcher to go and do the confirmatory analysis to see the bolts and nuts of the similarity is not a proper candidate for the hierarchical clustering.

In K-Means method, $\mathrm{K}$ refers to the number of clusters that are favorable for the study and is defined by the researcher. The algorithm starts by comparing the initial means in the data set and their distances to the center of the dataset. This geometric logic allows the cases to be defined similarly. In other words, cases with the most similarity in terms 
of their distance from the center are located at one cluster. However, the results of clustering analysis cannot be non-exclusive.

This method is fed by the results of factor analysis. The scale of factor analysis at $\mathrm{R}$ method allows the latent variable to be shown in the analysis. Put simply, owing to the latent nature of the factors chosen for cluster analysis, each factor has an effect on the others. These effects that will be reported in correlation matrix at the end of the reports of factor analysis will be trivial.

The analysis has the step by step procedures to eliminate the variables out of the factor analysis to get the least correlation among variables as well as having clear sets of factors with distinct variables. Hence, the clustering methods should be given the most exclusive results. Besides, another favorable option that is used for the cluster analysis is a complete rather than partial clustering. The partial clustering allows cases to be remained without a cluster. This effect is shown while the assigned cases equal the number of cases used in all the clusters or the $100 \%$ usage of the cases at the end of the clustering. 


\section{4- Results}

This chapter contains all the reports for the results of analysis. Starting from the sample, the reliability test reveals that this sample is valid for the rest of the analysis. Results of factor analysis will be summarized in the tables explaining how many questions are allocated to each factor and what effects each factor is showing according to the questions it has. Finally, results of the non-hierarchical (K-means) clustering analysis are reported. The results will show how many cases each cluster has and what kind of effects each cluster shows. This method proves or rejects the null-hypothesis and is a ground for the discussion and conclusion of this study.

\subsection{Sample's characteristics}

The dataset were found helpful because the variety of questions that were asked in different way had covered so many areas that did not lead to the change in theoretical model of this research. In fact, the results would add into the perspective chosen for this research because of the nature of explorative studies. This brought about real learning points that were hidden at the first time to the eyes of researcher. In reporting the results and interpreting the implications of this research there are some interesting points for the researcher and would be of interest to the readers.

In order to produce a consistent analysis, tests for the consistency of the results and reliability of them are crucial. These two tests were performed on the dataset through SPSS's reliability test in which the results are internal consistency and reliability analysis 
of the sample. Cronbach's $\alpha$ estimate of internal consistency associated with the scores that can be derived from the scale of composite scores. Absence of reliability is crucial in achieving valid analysis so this test will assure the reliability of further analysis.

Appendix 3- Reliability of the sample- summarizes the result of reliability test for the consideration. It shows with the Cronbach's $\alpha$ of 0.833 this sample is well placed on the acceptable range $>0.50$ so these sets of factors meet the requirements suggested by Kohtamaki et al. (2012). In addition, the valid number of respondents to these sets of questions is 295 which still falls in the range of good number ( $\mathrm{n}=200$-to-300) of sample for the analysis based on the Tabachnick and Fidell (2001) suggestions.

\section{2 $\mathrm{R}$ factor analyses}

The results for factor analysis would be the same if this study had chosen the Q technique. The argument about the difference between the factor analysis method is enlightening for researchers to avoid the fallacies of each method and be cautioned about

the predicaments of them (Stewart, 1981). Therefore, the choice of this method was based on the reasons related to the research methodology as explained in the previous sections.

This study finds the R factor analysis more helpful because the software package used for this research would not affect the results. If any problem is found on the analysis, there will be a clear reason for that. Whether the method used usually causes that anomaly or there is an error with the dataset. Given the variances, means, and correlation coefficients 
of each factor, the interpretations of results of factor analysis with SPSS would not be affected by differences they show.

Stewart (1981) recommends that the interpretation of R factor analysis results become more evident when the means and variances are considered; rather, the coefficients' correlations may be distracting. Table 5 that shows two sets of questions separated from each other is produced as the result of tracking changes in means and variance of factors shown on the factor leadings. A quick test of Stewart's (1981) recommendations shows that, although the factors of trust and commitment have shown to be separate in the literature, which means they should show the low correlation coefficients and should be separated on this analysis, they are highly correlated. This can be the results based on the fundamental belief of respondents that the two are equal, meaning that they are not contentiously separating them from each other.

Since the suggestions found in the literature regarding how to do factor analysis are not specifically tailored for issues related to trust and commitment studies, this research opts for selecting factors based on the general suggestions mentioned above and analyzes the variance and means rather than correlation coefficients.

Results of factor analysis have shown acceptable categorization of variables based on the correlation between the answers to each category of questions. Firstly, the extracted number of factors is 5 and they categorize the question set that aimed to evaluate the atmosphere of relationships into two groups, which are favorable to this study. As table 5 
shows the factor number 1 is chosen as an indicator of trust. Information sharing and honesty in between the partners suggest this choice of name as it complies with the social capital literature mentioned in the previous chapters.

Factor 3 on the SPSS output has the most similarity to the commitment issues related to partnership of the firms. Indicating the sacrifices is the dominant answer to the questions in this category of questions so for that purpose, and in addition to the reason that these question are the only remaining ones out of the questions determined to be showing the relationship capital levels, the name of Commitment is chosen for this factor. Table 5 outlines the most important values shown on the factor analysis such as factor loadings, Eigenvalues, cumulative percentage of variance and item to total correlations. Factor 1 with the specified factor loadings regarding each variable and Eigenvalue 5.899 composes $22.625 \%$ of the variation on the dataset. For factor 3, commitment the Eigenvalue is 2.098 and it composes $40.673 \%$ of variations. 


\begin{tabular}{|c|c|c|c|c|}
\hline Factor analysis results & $\begin{array}{l}\text { Factor } \\
\text { loading }\end{array}$ & Eigenvalue & $\begin{array}{l}\text { Cumulative } \% \\
\text { of variance }\end{array}$ & $\begin{array}{l}\text { Item-to-total } \\
\text { correlation } \\
\mathrm{h}^{2}\end{array}$ \\
\hline $\begin{array}{l}\text { Factor 1: } \\
\text { TRUST } \\
\text { a_5_3: We are convinced that the } \\
\text { supplier is able to keep our } \\
\text { information confidential } \\
\text { a_5_4: Our success is very } \\
\text { important to the supplier } \\
\text { a_5_5: We can trust the supplier } \\
\text { supports us in matters that are } \\
\text { important to us } \\
\text { a_5_6: We believe that the supplier } \\
\text { is frank/honest } \\
\text { a_5_7: We can trust that the supplier } \\
\text { considers the effects of their } \\
\text { decision making on our operation } \\
\text { a_5_8: We are fully convinced of } \\
\text { the supplier's skills and competence } \\
\text { a_5_9: It is highly probable that we } \\
\text { will not be doing business with the } \\
\text { supplier in next two years } \\
\text { a_5_10: We are happy to collaborate } \\
\text { with this supplier } \\
\text { a_5_11: We believe this will be a } \\
\text { long-term supplier relationship }\end{array}$ & $\begin{array}{l}.583 \\
.488 \\
.812 \\
.670 \\
.496 \\
.737 \\
-.454 \\
.624 \\
.619\end{array}$ & 5.899 & 22.625 & $\begin{array}{l}.298 \\
.333 \\
.563 \\
.508 \\
.379 \\
.467 \\
.308 \\
.467 \\
.402\end{array}$ \\
\hline $\begin{array}{l}\text { Factor 3: } \\
\text { COMMITMENT } \\
\text { a_5_12: We are willing to sacrifice } \\
\text { effort and money to maintain and } \\
\text { develop this supplier relationship } \\
\text { a_5_13: We are ready to shield this } \\
\text { supplier if anyone criticize them } \\
\text { (their operation) } \\
\text { a_5_15: We are very committed to } \\
\text { this supplier } \\
\text { a_5_16: We are ready for short-term } \\
\text { sacrifices to maintain a healthy } \\
\text { relationship with this supplier } \\
\text { a_5_17: We would agree if the } \\
\text { supplier asked to invest more in } \\
\text { order to support their operation } \\
\text { a_5_18: We do not want to make } \\
\text { additional effort or investments to } \\
\text { develop this supplier relationship }\end{array}$ & $\begin{array}{l}.567 \\
.415 \\
.586 \\
.816 \\
.734 \\
-.388\end{array}$ & 2.098 & 40.673 & $\begin{array}{l}.376 \\
.334 \\
.356 \\
.467 \\
.453 \\
.189\end{array}$ \\
\hline
\end{tabular}

Table 5- Factor Analysis results for the RC constructs 
As Table 6 shows, SPSS categorized the questions on the expectation and realization of those expectations into 3 groups. Factor 2 contains 5 questions that in this context is called seeding the options. This is because of the close similarity of the questions asked on this question set to the stories and cases defined by Baghai et al. (1999). With the Eigenvalue of 3.211 , these questions comprise $34.030 \%$ of the cumulative variance.

Factor 4 that comprises of questions related to the improvement of the processes and the use of new technology into the company called Managing profitability. This factor with the Eigenvalue of 1.571 explains $45.624 \%$ of cumulative variance. Factor 5, in SPSS output, called Testing and replication. This stage of growth has the characteristics related to the market data gathering and supplier's test for their support for implementing a new plan. As the results of this analysis show, respondents were asked to evaluate the supplier's role in this stage through answering to questions regarding the price of the suppliers' products and the information they can attain from the suppliers regarding the products and feedback from customers. This factor 5 has Eigenvalue of 1.244, a small difference from the previous factor, and it represents $49.300 \%$ of the variance in total.

\begin{tabular}{|l|l|l|l|l|}
\hline $\begin{array}{l}\text { Factor analysis of relationship } \\
\text { capital }\end{array}$ & $\begin{array}{l}\text { Factor } \\
\text { loading }\end{array}$ & Eigenvalue & $\begin{array}{l}\text { Cumulative \% } \\
\text { of variance }\end{array}$ & $\begin{array}{l}\text { Item-to-total } \\
\text { correlation } \\
\mathrm{h}^{2}\end{array}$ \\
\hline $\begin{array}{l}\text { Factor 2: Seeding Options } \\
\text { a_6_9: Getting supplier's support } \\
\text { (acceptance?) in building and } \\
\text { developing relationships to other } \\
\text { suppliers } \\
\begin{array}{l}\text { a_6_10: Creating new customer } \\
\text { relationships } \\
\text { a_6_11: Access to important } \\
\text { industry committees and }\end{array}\end{array}$ & .529 & 3.211 & 34.030 & .433 \\
\hline
\end{tabular}




\begin{tabular}{|l|l|l|l|l|}
\hline $\begin{array}{l}\text { organizations } \\
\text { a_6_12: Creating contacts to people } \\
\text { who are important to our business }\end{array}$ & .824 & & & \\
\hline $\begin{array}{l}\text { Factor 4: Managing Profitability } \\
\text { a_6_13: Improvement of current } \\
\text { products and development of new } \\
\text { products } \\
\text { a_6_14: Improvement of current } \\
\text { production processes and } \\
\text { development of new processes } \\
\text { a_6_15: Use of new technology in } \\
\text { our company }\end{array}$ & .720 & .819 & 45.624 & .427 \\
\hline $\begin{array}{l}\text { Factor 5: Testing and replication } \\
\text { of BIs } \\
\text { a_6_4: Fast delivery times, when } \\
\text { another (the usual) supplier is } \\
\text { unable to deliver to us in a rapid } \\
\text { schedule }\end{array}$ & .859 & 1.244 & 49.300 & .616 \\
$\begin{array}{l}\text { a_6_5: Becoming less dependent on } \\
\text { other supplier's (and their products) }\end{array}$ & & & & .532 \\
\hline
\end{tabular}

Table 6-Factor Analysis results for Growth Strategy Constructs

In order to interpret the results of factor analysis, which are used for cluster analysis in later sections, a development of the concept used for questions of this part of the analysis is needed. These interpretations are based on the sequence of factor analysis and cluster analysis and mentions here without numbers they associate with in the questionnaire.

Firms in the questionnaire are asked if they are convinced that the supplier has shown integrity in keeping their shared information secretly and believe that their performance is important to their suppliers. They were asked if they see the supplier supports them unconditionally and the supplier considerate of the effects that its decisions may have on the firm's operations. These firms also were asked that if trust has some reciprocity in their relationships as they feel it or not. In another question they answered to the question 
about the probability of not working with this supplier and if they are happy with the collaboration environment and will see the relationship as the long term one.

Moreover, questions were asked about firms' commitment in terms of their willingness to sacrifice money and efforts to maintain and develop relationships. They were asked if they are ready to shield the criticism that the suppliers are subjected to and if they see short-term sacrifices as a sign of healthy relationships with their supplies. In addition to the straight question on how much they are committed to the suppliers, the followed question asked for endorsement of their response by giving them a question about their willingness to invest in suppliers' choice of improvement area in their own firms and if they don't want to make additional effort or investments to develop the relationship they have with the supplier (see Appendix 1).

On the growth strategies, firms were asked to show on what extent their expectations of relationships were turned into reality. Three categories of answers were found based on the results of factor analysis. Firms were asked on "Getting supplier's support “, "Creating new customer relationships" through their suppliers, and having "Access to important industry committees and organizations". These items represent the seeding option stage of growth strategy. Moreover, firms were asked to weigh their dependability on suppliers and possibility of purchasing large quantities of specific product in future from them. 
Ensuring long-term sustainability of delivery, improvement of current products and development of new products, improving the current production processes and developing new processes, and possibility of using new technology in their company through their suppliers' relationship were the remaining 3 out of 5 questions in which firms were asked to demonstrate their relationship benefits. In this research, such questions were categorized as "managing profitability". According to the factor analysis questions selected for "test and replication of business ideas" asked if firms consider fast delivery times when another (the usual) supplier is unable to deliver to us in a rapid schedule, also if they become less dependent on other supplier's (and their products) through their relationships with this specific supplier.

\subsection{Cluster Analysis}

K-means analysis starts with assigning each cluster case by case. As the results of the initial analysis shows, on the first round of the assigning cases, firms with negative means on trust and commitment are categorized with the cases that have negative means in their growth strategy steps (Cluster 1). Moreover, existence of positive means for both of the effects of relationship capital shows to be positively correlated to the means of factors for growth strategies (Cluster 3). The table below shows the summary of initial cluster values. 


\begin{tabular}{|l|r|r|r|r|}
\hline & \multicolumn{4}{|c|}{ Cluster } \\
\cline { 2 - 5 } & 1 & \multicolumn{1}{|c|}{2} & \multicolumn{1}{c|}{3} & \multicolumn{1}{c|}{4} \\
\hline Trust & -1.70260 & -3.65152 & 1.61839 & 1.40587 \\
Seeding Options & -.71057 & .70374 & 1.71017 & -1.04152 \\
Commitment & -.51251 & -.39328 & 2.36337 & 1.65467 \\
Managing Profitability & -1.33028 & 1.52712 & .51409 & -1.61591 \\
Testing \& replicating business ideas & -2.12960 & .92439 & -1.52496 & 1.52508 \\
\hline
\end{tabular}

Table 7- Initial cluster centers

As cluster analysis ran for 300 cases, respondents were gradually assigned to each cluster based on their answers to Relationship evaluations (Trust, Commitment) on their realization of the effects of the partnership on their firms' growth related performances such as seeding options for future growth, test and replication of new business ideas into the market, and managing the profitability of new ideas. The missing 46 cases were those with no answers to the questions that they were asked to; however their population size in the sample needs a careful interpretation for their effects on the other clusters.

A non-hierarchical cluster analysis using K-means method was ran several times but the produce of four clusters gave the optimum number of cases within each cluster and accordingly significant results (with 95\% confidence interval). Although this test was conducted four times by different choice of the clusters ( 2 through 5 ), they were not all 
significant; among those clusters, center values of means were significantly different from the observed means of each case.

In fact, the clusters in analyses that gave output of 2,3 , and 5 clusters had low distance in between clusters and low association among the members of clusters. Hence, the choice on the number of clusters should be taken through deduction from literature review and compliance with the null hypothesis. With the cluster 1 that comprises 79 cases of the total, cluster 2 contains 66 cases, and cluster 3 and 4 with 87 and 68 cases respectively, plus the 46 cases which were missing in their value of associate variables the whole 346 cases and responses found to be distributed among the clusters at the highest favor of this research (Table 8).

Number of Cases in each Cluster

\begin{tabular}{|lr|r|}
\hline & 1 & 79.000 \\
Cluster & 2 & 66.000 \\
& 3 & 87.000 \\
& 4 & 68.000 \\
Valid & & 300.000 \\
Missing & 46.000 \\
\hline
\end{tabular}

Table 8- Population of clusters

While the results are showing the four clusters that each might have valuable explanation for other experiments, the third cluster that has the highest number of cases and some interesting results to show, rejects the null-hypothesis of the research (see Figure 3). 


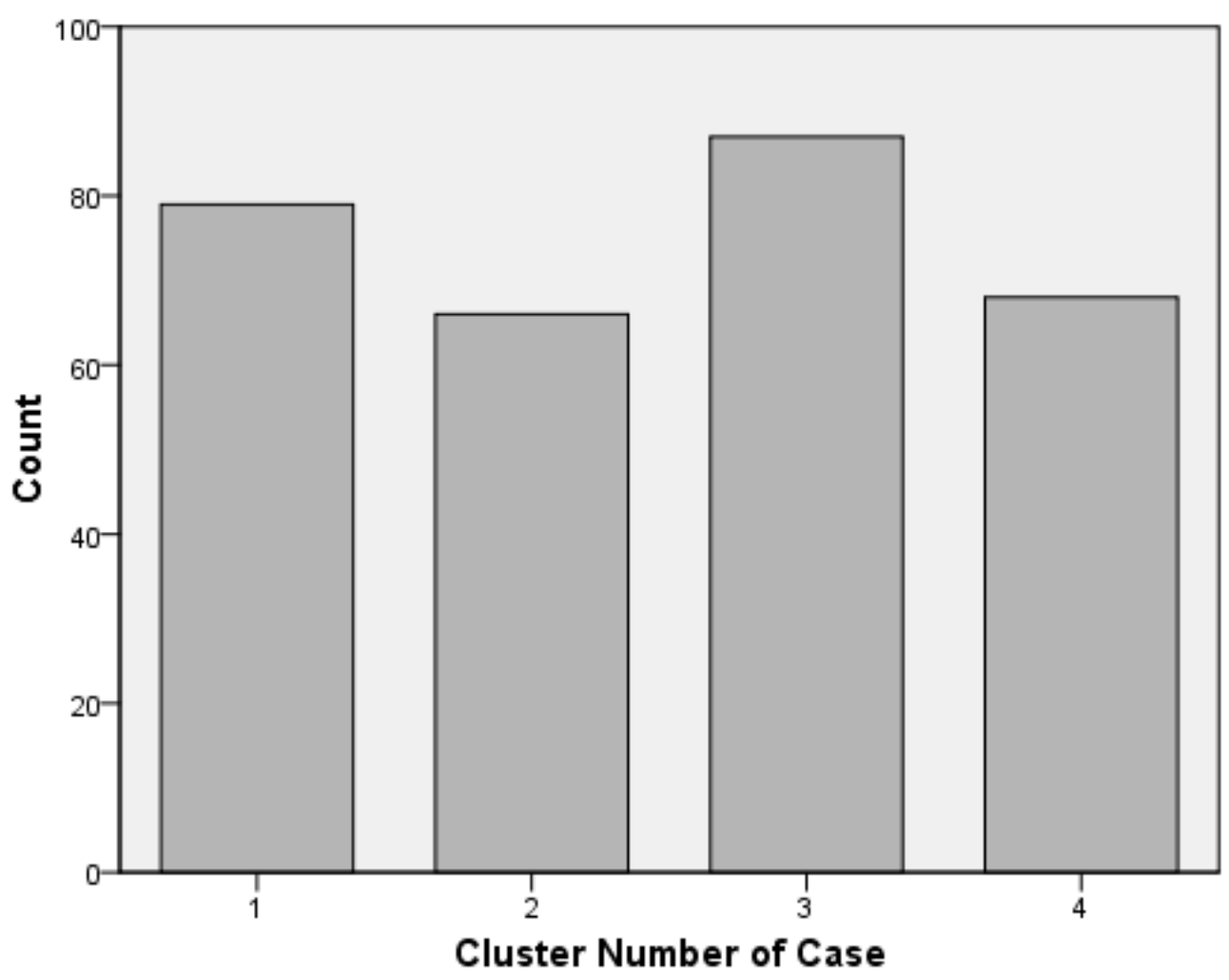

Figure 3- Distribution of cases per clusters

In addition to significance, ANOVA results indicate that " Trust" $(\mathrm{F}=64.038, \mathrm{df}=3, \mathrm{p}=$ 0.05), "Commitment" ( $F=72.025, \mathrm{df}=3, \mathrm{p}=0.05)$, "Seeding options" $(\mathrm{F}=223.416, \mathrm{df}=$ 3, $\mathrm{p}=0.05)$, "Managing profitability" $(\mathrm{F}=127.014, \mathrm{df}=3, \mathrm{p}=0.05)$, and "Test and replication of business ideas" $(\mathrm{F}=48.035, \mathrm{df}=3, \mathrm{p}=0.05)$ are all significant to reject the null hypothesis related to each cluster (see Table 9). It shows that the "seeding option" and "managing profitability" has the most contribution to the variation of other variables because their mean squares are higher than others. 


\begin{tabular}{|c|c|c|c|c|c|c|}
\hline \multicolumn{7}{|c|}{ ANOVA } \\
\hline & \multicolumn{2}{|c|}{ Cluster } & \multicolumn{2}{|c|}{ Error } & \multirow[t]{2}{*}{$\mathrm{F}$} & \multirow[t]{2}{*}{ Sig. } \\
\hline & $\begin{array}{c}\text { Mean } \\
\text { Square }\end{array}$ & $\mathrm{df}$ & $\begin{array}{c}\text { Mean } \\
\text { Square }\end{array}$ & $\mathrm{df}$ & & \\
\hline Trust & 34.336 & 3 & .536 & 296 & 64.038 & .000 \\
\hline Seeding Options & 62.429 & 3 & .279 & 296 & 223.416 & .000 \\
\hline Commitment & 34.710 & 3 & .482 & 296 & 72.025 & .000 \\
\hline $\begin{array}{l}\text { Managing } \\
\text { Profitability }\end{array}$ & 47.939 & 3 & .377 & 296 & 127.014 & .000 \\
\hline $\begin{array}{l}\text { Testing and } \\
\text { replication of BI }\end{array}$ & 26.726 & 3 & .556 & 296 & 48.035 & .000 \\
\hline
\end{tabular}

Table 9-ANOVA table

Cases (companies) in the first cluster have shown none of the relationships that were supposed to be measured in this study. The firms have no growth and no relationship capital. The mean of the cluster in each of the categories that were undergoing for measurement was negative, but the results are significant meaning that the companies are not randomly or with high rate of error assigned to the cluster.

The second cluster comprises of 66 cases with all the negative means for the variables designed to measure relationship capital; however the measurements of growth are shown positive in this cluster. Companies that do not benefiting from the relationship with partners and not helping them with their aid are those that believed their expectations of their relationships have been turned into reality though.

The third cluster with the largest number of cases (87) contains firms that have relationship capital and that enjoy the positive performance of growth. This cluster of firms has positive means with regards to the variables of this research. On average these 
firms have denoted that positive relationship capital leads to the positive performance of growth strategies and their expectations of relationship have also been realized.

The fourth cluster contains 68 cases with positive indication of what they have as relationship capital, have negative realization of their expectations in regards to growth strategies. While their average response to whether they have trust and commitment in their relationships with partners or not was positive, their mean of responses to the growth performance indicators were all negative (see Table 10).

Final Cluster Centers

\begin{tabular}{|l|l|l|l|l|}
\hline \multirow{2}{*}{ Trust } & \multicolumn{4}{|c|}{ Cluster } \\
\cline { 2 - 5 } & \multicolumn{1}{|c|}{1} & \multicolumn{1}{c|}{2} & \multicolumn{1}{c|}{3} & \multicolumn{1}{c|}{4} \\
\hline Seeding options & -.80231 & -.29815 & .63055 & .41475 \\
Commitment & -.81795 & .35820 & 1.02632 & -.71048 \\
& -.90944 & -.04321 & .59792 & .33352 \\
Managing Profitability & -.81891 & .39604 & .84666 & -.51625 \\
Testing and replication of BIs & -.76098 & .23608 & .58823 & -.09765 \\
\hline
\end{tabular}

Table 10-Final Cluster centers

Firms in cluster 3 showed positive relations between questions in all 5 factors, i.e. trust and commitment on relational capital, seeding options, testing and replication of business ideas, and managing profitability. This cluster illustrates that there is a positive 
relationship between relationship capital constructs and growth strategy steps. This would reject the test 1's null hypothesis and accept the alternative hypothesis. It is supported by the abundance of literature on SC from the transaction based view that would show the link between SC and the growth of the firms (e.g. Westerlund \& Svahn, 2008).

\section{Distances between Final Cluster Centers}

\begin{tabular}{|l|l|l|l|l|}
\hline Cluster & 1 & 2 & 3 & 4 \\
\hline 1 & & 2.204 & 3.510 & 1.889 \\
2 & 2.204 & & 1.431 & 1.654 \\
3 & 3.510 & 1.431 & & 2.337 \\
4 & 1.889 & 1.654 & 2.337 & \\
\hline
\end{tabular}

Table 11- Distance between cluster centers

Clusters are in a distance from each other, showing that the results are categorized properly by the SPSS software. As Table 11 shows the maximum distance is 3.510 and it happens between clusters 1 and 3, the most valued clusters that are related to the hypotheses of this research and errors of analysis. This also proves the choice of cluster 3 with higher number of cases as the main source of rejecting null-hypothesis because this cluster has also well been differentiated from the other cluster. Rejecting this hypothesis leads to accepting the alternative hypothesis that states there is a positive effect on the performance if the relationship capital exists.

\section{5- Discussion and conclusion}

Results of cluster analysis showed that the assumptions about the relationship capital were all true, even though this study has a different approach - as compared to previous 
researches used for developing constructs of this study - to investigate its effect on the firm's growth. This study has tried to show that the term of capital is explainable through resource-based studies denoting trust and commitment as attributes of abilities and resources. Capability of a firm increases upon attainment of $\mathrm{RC}$ that help the firm to achieve growth. The resource based view enabled the researcher to argue that RC can be measured in its impacts on growth of the firm. Aligned with that argument, statement of null hypothesis of this research asserted that no RC impacts can be measured for the effects of RC on growth of the firms. And the results of this research rejected such a statement and showed that the impact of $\mathrm{RC}$ on growth of the firms is significant.

One way to show that the results of the study are reliable is to check the results based on the univariate comparisons of means. That is, the results of analysis and clusters are checked based on their means, and significance of the values for each cluster is revealed through descriptive statistic results of this test. Table 12 provides means, standard deviations, and counts for each cluster across levels of independent variables of research ( $\mathrm{RC}$ variables and Growth variables). Based on the results of this table, the highest effect of independent variables are found on the cluster 1 in which the mean is 1.668 . Cluster 3 has the second lowest means. However, possessing the lowest standard deviation and more number of cases in this research is interpreted as the factors that differentiate this cluster 3 from the others. 


\section{Descriptive Statistics}

\section{Dependent Variable: Distance of Case from its Classification Cluster Center}

\begin{tabular}{|l|l|l|l|}
\hline Cluster Number of Case & Mean & Std. Deviation & N \\
\hline 1 & 1.6678920 & .57368530 & 79 \\
3 & 1.1702537 & .50489569 & 66 \\
4 & 1.2445755 & .51574093 & 87 \\
Total & 1.3959981 & .51734546 & 68 \\
\hline
\end{tabular}

Table 12-Descriptive statistics for Univariate analysis

Looking at Levene's test of equality of error variances, it is endorsed that once again the variances among the clusters are equal so that the whole cluster analysis results are reliable for interpretation (see Table 13).

\section{Levene's Test of Equality of Error Variances}

\section{Dependent Variable: Distance of Case from its Classification Cluster Center}

\begin{tabular}{|c|c|c|c|}
\hline F & df1 & df2 & Sig. \\
\hline .745 & 3 & 296 & .526 \\
\hline
\end{tabular}

Table 13-Levene's test for Univariate analysis 
The "Tests of between subject effects" are demonstrated in Table 14. This table shows that the QCL_1 variable which iscreated to maintain the values of difference of each case's value from the center of cluster is significant. the significance of univariate analysis can be reported as, $\mathrm{F}(3,296)=13.132, \mathrm{p}<.001$, partial $\eta^{2}=.117$. The values indicate that this assessment has the F value of 13.131 that is evaluated with 3 degrees of freedom between clusters and 296 within them and this clustering test accounts for $11.7 \%$ of the total variance in assessment of RC-Growth relationship.

\section{Tests of Between-Subjects Effects}

\section{Dependent Variable: Distance of Case from its Classification Cluster Center}

\begin{tabular}{|l|l|l|l|l|l|l|}
\hline Source & $\begin{array}{l}\text { Type III Sum } \\
\text { of Squares }\end{array}$ & df & Mean Square & F & Sig. & Partial Eta \\
\hline Corrected & $11.053 \mathrm{a}$ & 3 & 3.684 & 13.132 & .000 & .117 \\
Model & 555.757 & 1 & 555.757 & 1980.829 & .000 & .870 \\
Qntercept & 11.053 & 3 & 3.684 & 13.132 & .000 & .117 \\
Error & 83.048 & 296 & .281 & & & \\
Total & 660.481 & 300 & 299 & & & \\
\hline
\end{tabular}

Table 14-Tests of between-Subjects Effects for Univariate analysis 
The reported results above are subjected to the errors that might be happening through the null-hypothesis examination. Table 15 shows when these errors happen and what they are.

\begin{tabular}{|l|l|l|}
\hline Decision & True H0 & False H0 \\
\hline Accept H0 & Type I & Correct \\
\hline Reject H0 & Correct & Type II \\
\hline
\end{tabular}

Table 15- Errors of null hypotheses

Type I error occurs when the results reject the true hypothesis. This happens usually the time that the researcher's interpretation of the reality, or in this research the theory, fall short to support the neutral direction of the null-hypothesis. This is not the possible error for this research since the statements defined on the hypotheses section have been chosen against the reality or the previously proven studies. This study is grounded on the basis of previously researched phenomena in which the social capital and relational capital proven to be effective on the firm's growth.

The constructs of the research have been selected based on the extant models and the quality of theory cannot be under a shadow of doubt. The closer look at the hypothesis and results proves that. Test 1 that states the existence of relationship capital does not have impact on performance of growth strategies seems to be error free. The reason is a guideline from literature on the existence of relationship capital. In the literature review 
section, the study mentioned that firms with demonstrated signs of trust and commitment simultaneously will enjoy relationship capital.

Results of the analysis are also flawless in terms of the bias that researcher might have, combining methods (dimension reduction through factor analysis and cluster analysis together), and computational errors. This research availed itself from the previously gathered data. The collected data served an unbiased dataset for this research. Also the combination of methods has been vastly used in the literature (e.g., Kajalo et al. 2007), and the well-known SPSS statistical analysis software is a reliable tool that computes data with no error outside the known areas of research (e.g., it gives confidence interval of the final results).

Finally, the contradictory results of the final clusters with hypotheses of this research which might seem to be accepting null-hypothesis or even questioning its logic are not substantial to be cited as errors of this research. Although the contradiction exists, the literature that supports them does not. There has been no research, to the best of understanding of the researcher, which would support any results of the other clusters. Clusters that can demonstrate the lack of trust and commitment resulted in growth of the firms in the cluster, or vice versa, are not found.

Type II errors that are more expected in this research, seems to be happening with considerably higher possibilities. Expedited and uncontrolled answers to the questions that exist in any data gathering processes will lead to this kind of error, type II. The 
results may be subjected to this error since the number of missing cases or not-assigned cases to the clusters is not low enough to reject the possibility of having the errors like this. In short, this research may have errors that are the results of processes or phenomena that are not under control for the researcher.

In sum, results of this study show that from the resource-based view of a firm, companies are capable to compete with a higher edge against the stream if they develop their relationships and invest on keeping the flow of benefits in their relationships alive. Firms of subject of this study were openly accepting integration of the feedbacks from suppliers and spending them on improvements of processes or products whenever it was necessary.

The reciprocity of exchange in benefits as well as their trust in the relationships has built their relationship in a way that called capital. This study also shows that firms can benefit from the relationship as they did by achieving growth. Their growth found to be reliant on the existence of relationship capital, and this is recommended in the literature as the capacity that would be hard to imitate and make them lead them in a market competition.

\subsection{Dataset selection}

The dataset acquired for this research comprised respondents from outside Canada. There are pros and cons to this choice. Use of such dataset was advantageous to check the generalizability of the proposed model. The model coming out of the theory has justified the respondents' opinion on the effects of trust and commitment for their firm's growth. 
The neutral interviewers, objective to the purpose of this research collected the dataset. This is one of the boldest positives about this dataset that is favorable for this research.

On the contrary, direct interviews by the researcher that could lead to better understanding the phenomena are missing in this research. Different rounds of conversations and interviews would shed more light on the interactions as well as the direct results of partnerships to the firm's growth. They could help in designing a more specific questionnaire, whereas the current questionnaire of the data set used for the analysis was collected by other researchers and for other purposes. In addition, the test is performed on the cross-examined dataset whereas the majority of research on social and relational capital suggests the longitudinal studies as the proper method.

The overall conclusive remark to this trade-off between pros and cons would be that negative and bias related to the dataset always exists in a research. Furthermore, a longitudinal study of the phenomena may be impossible for the resource-based category of research as the previous literature on this stream has systematically avoided doing that.

\subsection{Research anomalies}

This study aimed for investigating signs for the concept of relational capital within a firm. This research was availed of a previously collected dataset that the hypotheses of this research were examined on. Although data were collected based on the broader research purpose, quality of this research has not been influenced. Close match between 
the questions of the dataset and those of similar researches on SC-growth that all were reported in proper sections of this research helped keeping good quality of analysis.

The data set for this research was undergone correction for missing and unclear data before starting analyses, and the primary data collectors were asked for some clarifications about the questions to find the most proper match for this research and avoid interpreting false anomalies. However, the analysis has shown some of the anomalies that are listed here.

During the factor analysis, dimension reduction, questions from the opposite categories and meanings were shown slightly high to high correlations with each other. For example, "a_6_3: Supplier's ability to offer valuable services related to their products" was one of those questions with overlap to the trust factor that was eliminated from the results. In addition, questions like "a_5_1: We think the supplier is telling us the truth even their explanation sounds incredible/difficult to believe" and "a_5_2: The supplier has often provided us with information that turned out to be incorrect" were shown with cross loadings all over the five factors or by suppressing the results of the factor analysis (lower than 0.30 in Eigenvalues), they did not show any signs on the factors. It is assumed that these questions have had an effect for the overall classification of the clusters; however, the factors used for the cluster analysis were the direct inputs from factor analysis. 
Besides the anomalies related to factor analysis, clustering of the cases showed some of disarrangement with the favorable results of this study. As reported, results of a 2 cluster analysis were shown non-significant despite the near equal number of cases that the two clusters had. Indeed, meeting the theory criteria would not be conducive to the results of the cluster analysis. Furthermore, the results of a 3 clustered analysis were significant, but they did not suggest any specific number in terms of differences between clusters, and the number of cases that were not assigned was high. Choice of number for 4 clusters has shown some anomalies in terms of the number of cases per each cluster. Number of cases in a cluster that helped rejecting the null-hypothesis was slightly higher than the others. This effect, although it has been covered by the significant difference between the means of each cluster, is one of the anomalies of analysis.

\subsection{Managerial insights}

The extant literature on SC proposes context-specific models for growth. Westerlund and Svahn's (2008) model for a firm's growth consider the vicinity and mutuality that makes relationship with partners from transactional perspective. The longitudinal studies of relational capital ensue the results being more indirect to micro levels of growth that are useful for pinpointing the firm's operations towards a successful growth. Relational capital, the third level aspect of social capital, is only traceable in small firms. This is because of the structural properties that these firms have. They are small in operations, the trivial effects of relational capital on them makes huge difference on the future perspectives they have. Besides, the relational properties that are available to these firms 
are fundamentally different from the large organizations thanks to the low hierarchical structure and the fact that the whole organization is engaged in the relationships.

The study believes that models that have been proposed in literature need more elaboration based on each firm's situation and so it reduces their usage rate. There has to be too much education load to manage the relationships that are not only leading to revenue but the longer term of contracts and mutual interactions. The current models of building social capital extant in the literature suggest mutual investments on R\&D. The time issue is also like a double edged sword for social capital and relational capital perspective for the small firms. These firms are intensive towards their revenue generation activities to report their performance as the sales generated on specific period. On the other hand, as suggested by existing models, time has to be passed for a relation to achieve the level of commitment and reliability for firms to expect the effects of capital. The author's belief is that the transactional lens to look at relational capital impedes the models effectiveness and practicality. In fact, the resource-based perspective to the capital has more easiness and realization in practice for the entrepreneurs and investors to work their relationships toward the expected results that are shown in literature.

The terms 'social capital' and 'relationship capital' are not demonstrating good values to the eyes of investors. Considering that paying for strange intangible assets like IPs that are not secure, one should not assume that talking about partnership values as the major source of capability for the firms interest investors. Hence, clear definition of RC with practical business considerations which were cited as the results of this study conveys 
partnership messages better. Despite of that, this research shows that firms are more capable for achieving ultimate growth by leveraging relations and using them. This research demonstrates that firms can build the stairwells of growth from their relationships with partners. They can build growth by trusting the information shared through their connections with partners and the commitment built via sacrifices and reciprocal exchanges.

Firms can attain growth through incorporating benefits of relationships including knowledge of the market, technology, and process improvement. Ideally they can improve their chances of success in new market entry by increasing the success rate of new product development ensued by relying on the market information shared by partners or using their complementary products. This brings up the importance of intangible resource management of competitive strategies as suggested by Daum (2006), in which the importance of competitive advantages underlies the connection that firms has to its partners.

In addition, firms can increase their quality-cost ratio by relying on the complementary offers by the partners to their products as well as decreasing costs associated with $R \& D$ investments for introducing new products. This study shows that one of the associated benefits of relationship capital is the use of partners' technologies as well as an access to market and product information. The main message for managers is to caution them against investments on the ways to access novel information, but rather they must focus on achieving the committed partners by investing on relationship with them. 


\subsection{Limitations}

As the previous research shows, respondents need to be followed up to add and incorporate their valuable ideas of improvement into the research. Methods and models could have been improved by using qualitative methods if access to the interviewees and respondents of the questionnaire was possible. Interpretation of the third cluster for instance, although theoretically correct, could have been this research's strongest point of difference from the other researches in this vein.

Nonetheless there was a fairly good support by the dataset for the hypotheses established in this research; dataset limitation has had some effects on the number of available hypotheses to be tested for this research. This research could have been more valuable to the small firms if it was possible to find another factor related to the size of the firms in the dataset. Therefore a dataset limited the categorization of the results. In addition, time limitation towards completing this research has had an effect on the amount of interpretation; but not the quality of the results. As the studies show, even the correction of questionnaire takes more than a month while the total time allotted for theses researches should be limited to certain academic milestones.

\subsection{Future research avenues}

This research has provided a new meaning to relationship capital via deductions from the various streams of research. The definition was tested in this study; however the statement needs more investigation from resource-based, capability-based, and firm's 
strategy point of views. Focusing research on areas where RC can play an improving role is of importance especially for small firms because $\mathrm{RC}$ can be traced easily in them also the serious impacts that increase in operational capability can play for these firms.

Results of this study encourage further research for explaining how capability of the firm increases by the help of partner relationships. As it showed on the results section, constructs of relational capital were traced both in success of the strategies and their failures. Research windows are open now to understand if they can change the failures to success or not. It has been tried to show that this power exists although the limitation of research did not allow more in-depth investigation. The question raised here is that whether there are some cases in which signs of relational capital have changed the rate of success of firm's growth strategies. Studies that show these properties should be adding much more to the theories of social capital and resource-based view of the firm.

Moreover, the result of cluster 1 in which firms' relationships were built based on trust but not on the commitment side is worth considering as a proper research question. An intriguing question to ask is to what extent the properties of relationship capital from resource based theory are strong that cannot lead to the major negative correlation between this attribute and the expected effects. Maybe the results of such study would better define the relationship capital aspects and attributes or develop new constructs for research in this vein. 
There is another related opportunity window for future research. This research used the isolating effects approach to investigate changes on the resources while relationship capital exists. Future research could check the competitive advantage of the firm from the strategic factor point of view. This area of knowledge would help building a link between research that investigates strategies of a firm towards growth from the resource-based theory of the firm and other researches related to relational capital. 
Appendices 


\section{Appendix 1- Questionnaire}

The nature (from the trust-commitment perspective) of the supplier relationship; (18 questions)

$5=$ totally agree, $4=$ agree, $3=$ neutral, $2=$ disagree, $1=$ totally disagree, $0=d o$ not $k$ now Evaluate the current nature/atmosphere of the (chosen important, long-term) supplier relationship...

a_5_1: We think the supplier is telling us the truth even their explanation sounds incredible/difficult to believe

a_5_2: The supplier has often provided us with information that turned out to be incorrect a_5_3: We are convinced that the supplier is able to keep our information confidential a_5_4: Our success is very important to the supplier

a_5_5: We can trust the supplier supports us in matters that are important to us a_5_6: We believe that the supplier is frank/honest

a_5 7: We can trust that the supplier considers the effects of their decision making on our operation

a_5_8: We are fully convinced of the supplier's skills and competence

a_5_9: It is highly probable that we will not be doing business with the supplier in next two years

a_5_10: We are happy to collaborate with this supplier

a_5_11: We believe this will be a long-term supplier relationship

a_5_12: We are willing to sacrifice effort and money to maintain and develop this supplier relationship 
a_5_13: We are ready to shield this supplier if anyone criticize them (their operation) a_5_14: We would not operate with any other supplier if it hurts this supplier relationship a_5_15: We are very committed to this supplier a_5_16: We are ready for short-term sacrifices to maintain a healthy relationship with this supplier

a_5_17: We would agree if the supplier asked to invest more in order to support their operation

a_5_18: We do not want to make additional effort or investments to develop this supplier relationship 
Expectations vs. realization in the supplier relationship; (15 questions).

$5=$ totally agree, $4=$ agree, $3=$ neutral, $2=$ disagree, $1=$ totally disagree, $0=$ do not know

Evaluate how well the following realized aspects meet your expectations in the (chosen, long-term) relationship...

a_6_1: Inexpensive prices of supplier's products

a_6_2: Detailed product information available/received from the supplier

a_6_3: Supplier's ability to offer valuable services related to their products

a_6_4: Fast delivery times, when another (the usual) supplier is unable to deliver to us in a rapid schedule

a_6_5: Becoming less dependent on other supplier's (and their products)

a_6_6: Possibility to purchase large quantities of a specific product

a_6_7: Ensuring long-term sustainability of delivery

a_6_8: Achieving crucial and valuable industry information

a_6_9: Getting supplier's support (acceptance?) in building and developing relationships to other suppliers

a_6_10: Creating new customer relationships

a_6_11: Access to important industry committees and organizations

a_6_12: Creating contacts to people who are important to our business

a_6_13: Improvement of current products and development of new products

a_6_14: Improvement of current production processes and development of new processes

a_6_15: Use of new technology in our company 


\section{Appendix 2- Factor Analysis}

\section{KMO and Bartlett's Test}

\begin{tabular}{|c|c|c|}
\hline \multicolumn{2}{|c|}{ Kaiser-Meyer-Olkin Measure of Sampling Adequacy. } & .836 \\
\hline \multirow{3}{*}{ Bartlett's Test of Sphericity } & Approx. Chi-Square & 2843.133 \\
\hline & df & 2 \\
\hline & Sig. & \\
\hline
\end{tabular}

Communalities

\begin{tabular}{|l|r|r|}
\hline & Initial & Extraction \\
\hline a_5_3 & .298 & .317 \\
a_5_4 & .333 & .298 \\
a_5_5 & .563 & .630 \\
a_5_6 & .508 & .527 \\
a_5_7 & .379 & .337 \\
a_5_8 & .467 & .506 \\
a_5_9 & .308 & .244 \\
a_5_10 & .467 & .465 \\
a_5_11 & .402 & .367 \\
a_5_12 & .376 & .391 \\
a_5_13 & .334 & .327 \\
a_5_15 & .356 & .368 \\
a_5_16 & .467 & .601 \\
a_5_17 & .453 & .526 \\
a_5_18 & .189 & .168 \\
a_6_4 & .532 & .625 \\
a_6_5 & .526 & .692 \\
a_6_9 & .433 & .438 \\
a_6_10 & .545 & .554 \\
a_6_11 & .723 & .799 \\
a_6_12 & .712 & .744 \\
a_6_13 & .427 & .500 \\
a_6_14 & .616 & .711 \\
a_6_15 & .576 & .695 \\
\hline
\end{tabular}

Extraction Method: Principal Axis

Factoring. 
Total Variance Explained

\begin{tabular}{|c|c|c|c|c|c|c|}
\hline \multirow[t]{2}{*}{ Factor } & \multicolumn{3}{|c|}{ Initial Eigenvalues } & \multicolumn{3}{|c|}{ Extraction Sums of Squared Loadings } \\
\hline & Total & $\%$ of Variance & Cumulative \% & Total & $\%$ of Variance & Cumulative $\%$ \\
\hline 1 & 5.899 & 24.581 & 24.581 & 5.430 & 22.625 & 22.625 \\
\hline 2 & 3.211 & 13.378 & 37.959 & 2.737 & 11.404 & 34.030 \\
\hline 3 & 2.098 & 8.742 & 46.701 & 1.594 & 6.643 & 40.673 \\
\hline 4 & 1.571 & 6.547 & 53.248 & 1.188 & 4.951 & 45.624 \\
\hline 5 & 1.244 & 5.184 & 58.432 & .882 & 3.677 & 49.300 \\
\hline 6 & 1.007 & 4.198 & 62.630 & & & \\
\hline 7 & .908 & 3.783 & 66.412 & & & \\
\hline 8 & .781 & 3.253 & 69.666 & & & \\
\hline 9 & .760 & 3.169 & 72.834 & & & \\
\hline 10 & .712 & 2.965 & 75.799 & & & \\
\hline 11 & .640 & 2.666 & 78.465 & & & \\
\hline 12 & .610 & 2.540 & 81.006 & & & \\
\hline 13 & .540 & 2.252 & 83.257 & & & \\
\hline 14 & .538 & 2.241 & 85.499 & & & \\
\hline 15 & .480 & 2.002 & 87.500 & & & \\
\hline 16 & .456 & 1.898 & 89.398 & & & \\
\hline 17 & .422 & 1.757 & 91.155 & & & \\
\hline 18 & .400 & 1.667 & 92.822 & & & \\
\hline 19 & .370 & 1.543 & 94.364 & & & \\
\hline 20 & .358 & 1.492 & 95.856 & & & \\
\hline 21 & .316 & 1.316 & 97.172 & & & \\
\hline 22 & .298 & 1.240 & 98.412 & & & \\
\hline 23 & .219 & .913 & 99.326 & & & \\
\hline 24 & .162 & .674 & 100.000 & & & \\
\hline
\end{tabular}


Total Variance Explained

\begin{tabular}{|c|c|}
\hline \multirow[t]{2}{*}{ Factor } & Rotation Sums of Squared Loadings \\
\hline & Total \\
\hline 1 & 4.121 \\
\hline 2 & 3.773 \\
\hline 3 & 3.245 \\
\hline 4 & 3.234 \\
\hline 5 & 2.322 \\
\hline 6 & \\
\hline 7 & \\
\hline 8 & \\
\hline 9 & \\
\hline 10 & \\
\hline 11 & \\
\hline 12 & \\
\hline 13 & \\
\hline 14 & \\
\hline 15 & \\
\hline 16 & \\
\hline 17 & \\
\hline 18 & \\
\hline 19 & \\
\hline 20 & \\
\hline 21 & \\
\hline 22 & \\
\hline 23 & \\
\hline 24 & \\
\hline
\end{tabular}

Extraction Method: Principal Axis Factoring.

a. When factors are correlated, sums of squared loadings cannot be added to obtain a total variance. 


\section{Scree Plot}

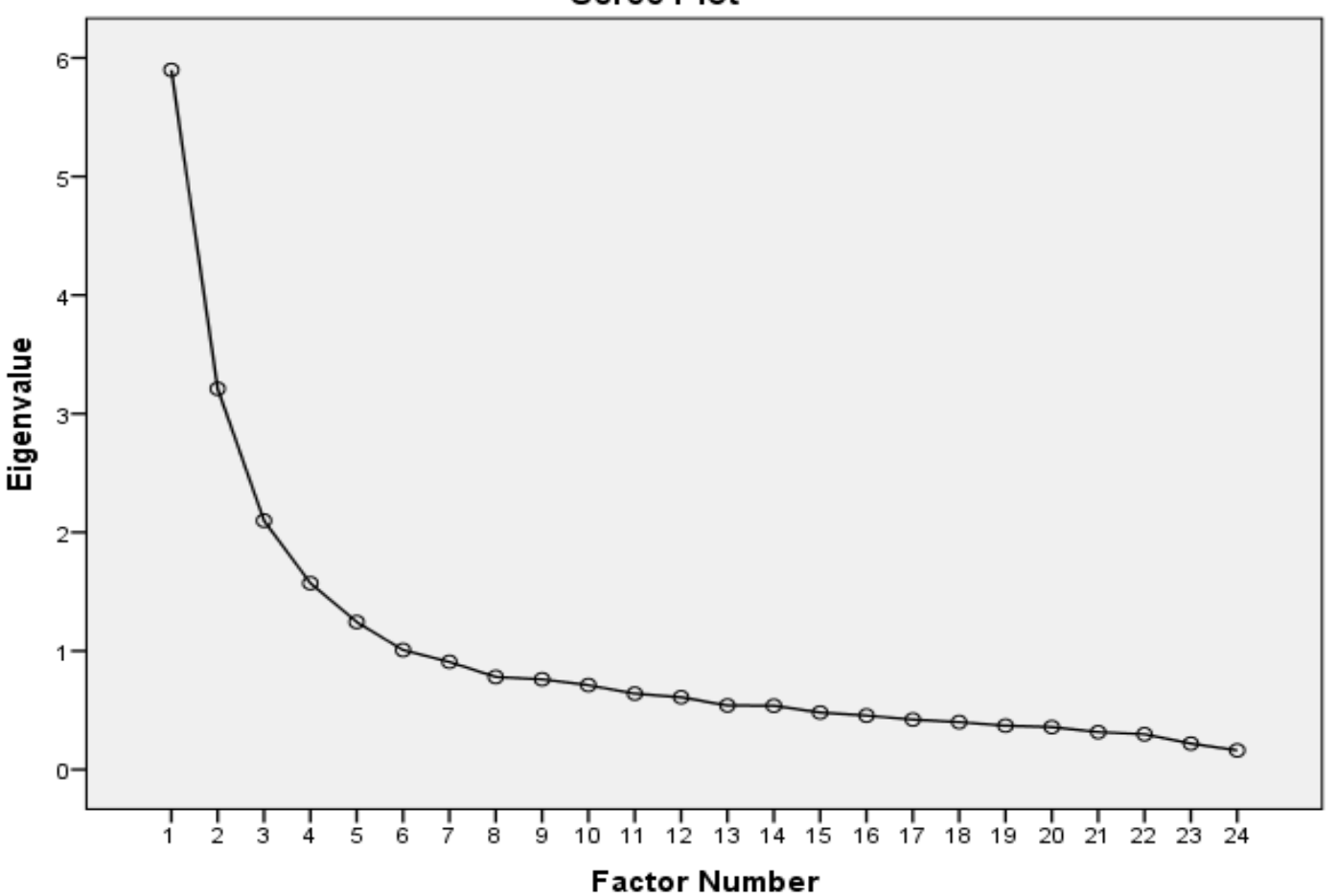


Factor Matrix ${ }^{\mathrm{a}}$

\begin{tabular}{|c|c|c|c|c|c|}
\hline & \multicolumn{5}{|c|}{ Factor } \\
\hline & 1 & 2 & 3 & 4 & 5 \\
\hline a_5_3 & .310 & -.423 & & & \\
\hline a_5_4 & .435 & -.311 & & & \\
\hline a_5_5 & .542 & -.505 & & & \\
\hline a_5_6 & .584 & -.383 & & & \\
\hline a_5_7 & .474 & -.325 & & & \\
\hline a_5_8 & .460 & -.493 & & & \\
\hline a_5_9 & -.305 & .376 & & & \\
\hline a_5_10 & .569 & -.351 & & & \\
\hline a_5_11 & .351 & -.463 & & & \\
\hline a_5_12 & .473 & & -.404 & & \\
\hline a_5_13 & .492 & & & & \\
\hline a_5_15 & .414 & & -.432 & & \\
\hline a_5_16 & .396 & & -.654 & & \\
\hline a_5_17 & .456 & & -.541 & & \\
\hline a_5_18 & & & & & \\
\hline a_6_4 & .386 & & & .566 & \\
\hline a_6_5 & .341 & & & .621 & \\
\hline a_6_9 & .515 & .375 & & & \\
\hline a_6_10 & .513 & .444 & & & \\
\hline a_6_11 & .624 & .442 & & & -.427 \\
\hline a_6_12 & .618 & .498 & & & \\
\hline a_6_13 & .444 & & & -.408 & \\
\hline a_6_14 & .629 & .305 & & -.328 & .334 \\
\hline a_6_15 & .548 & .352 & & -.310 & .402 \\
\hline
\end{tabular}

Extraction Method: Principal Axis Factoring. ${ }^{a}$

a. 5 factors extracted. 17 iterations required. 
Pattern Matrix ${ }^{\mathrm{a}}$

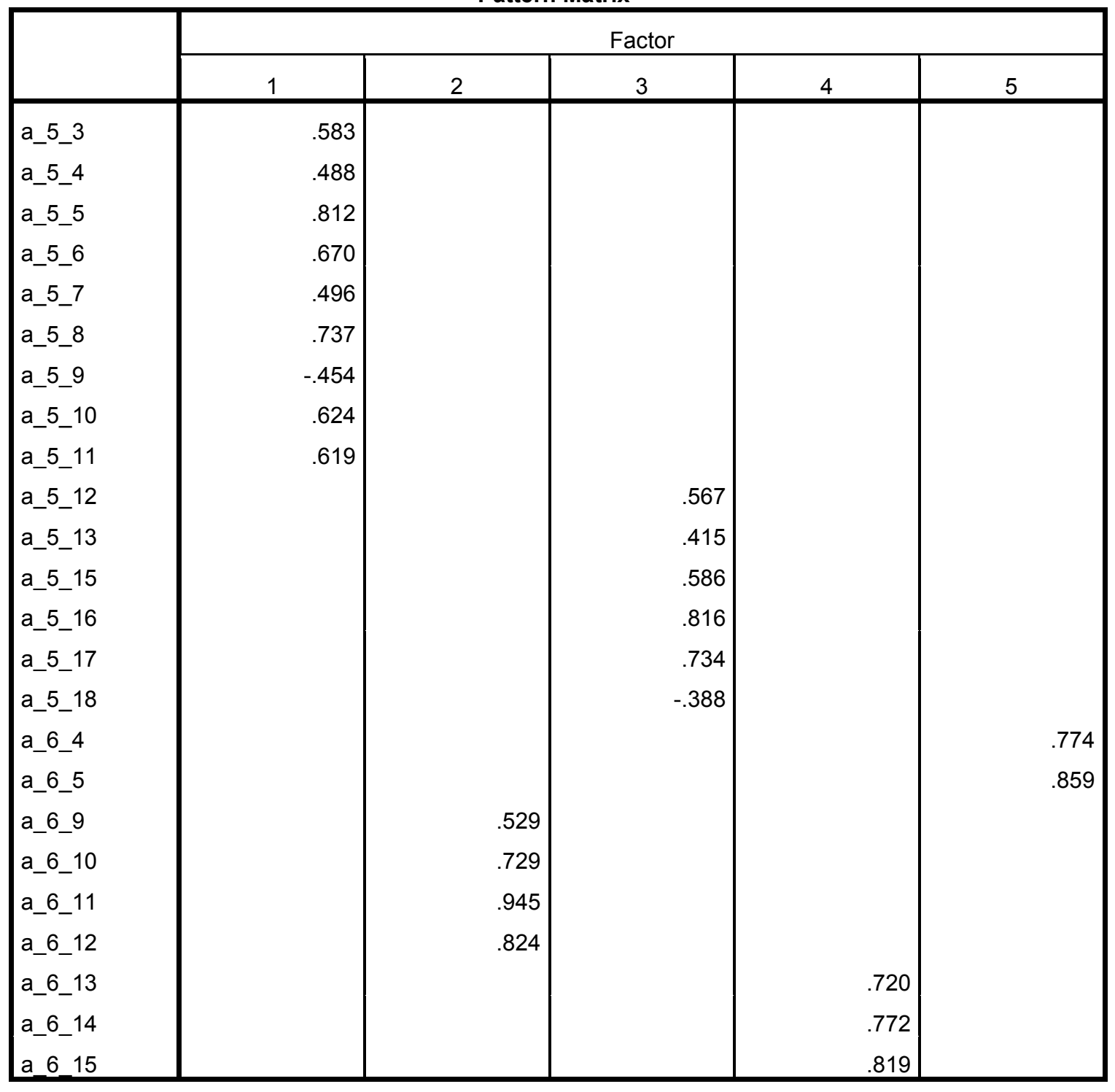

Extraction Method: Principal Axis Factoring.

Rotation Method: Promax with Kaiser Normalization. ${ }^{a}$

a. Rotation converged in 5 iterations. 
Structure Matrix

\begin{tabular}{|c|c|c|c|c|c|}
\hline & \multicolumn{5}{|c|}{ Factor } \\
\hline & 1 & 2 & 3 & 4 & 5 \\
\hline a_5_3 & .533 & & & & \\
\hline a_5_4 & .528 & & & & \\
\hline a_5_5 & .782 & & & & \\
\hline a_5_6 & .707 & & & & \\
\hline a_5_7 & .553 & & .339 & & \\
\hline a_5_8 & .701 & & & & \\
\hline a_5_9 & -.461 & & & & \\
\hline a_5_10 & .667 & & .302 & & \\
\hline a_5_11 & .581 & & & & \\
\hline a_5_12 & & & .612 & & \\
\hline a_5_13 & .400 & & .515 & & \\
\hline a_5_15 & & & .599 & & \\
\hline a_5_16 & & & .756 & & \\
\hline a_5_17 & & & .719 & & \\
\hline a_5_18 & & & -.391 & & \\
\hline a_6_4 & & .364 & & & .788 \\
\hline a_6_5 & & & & & .829 \\
\hline a_6_9 & & .640 & & .412 & .393 \\
\hline a_6_10 & & .742 & & .402 & .329 \\
\hline a_6_11 & & .888 & & .424 & \\
\hline a_6_12 & & .860 & & .504 & .357 \\
\hline a_6_13 & & .342 & & .697 & \\
\hline a_6_14 & & .510 & .329 & .838 & \\
\hline a_6_15 & & .462 & & .828 & .305 \\
\hline
\end{tabular}

Extraction Method: Principal Axis Factoring.

Rotation Method: Promax with Kaiser Normalization.

Factor Correlation Matrix

\begin{tabular}{|l|r|r|r|r|r|}
\hline Factor & \multicolumn{1}{|c|}{1} & \multicolumn{1}{|c|}{2} & \multicolumn{1}{c|}{3} & \multicolumn{1}{c|}{4} & \multicolumn{1}{c|}{5} \\
\hline 1 & 1.000 & .222 & .329 & .248 & .182 \\
2 & .222 & 1.000 & .308 & .528 & .407 \\
3 & .329 & .308 & 1.000 & .338 & .232 \\
4 & .248 & .528 & .338 & 1.000 & .284 \\
5 & .182 & .407 & .232 & .284 & 1.000 \\
\hline
\end{tabular}

Extraction Method: Principal Axis Factoring.

Rotation Method: Promax with Kaiser Normalization. 


\section{Appendix 3- Reliability of the sample}

Scale: ALL VARIABLES

\begin{tabular}{|c|c|c|c|}
\hline & & $\mathrm{N}$ & $\%$ \\
\hline \multirow{3}{*}{ Cases } & Valid & 295 & 85.3 \\
\hline & Excluded $^{a}$ & 51 & 14.7 \\
\hline & Total & 346 & 100.0 \\
\hline
\end{tabular}

a. Listwise deletion based on all variables in the procedure.

Reliability Statistics

\begin{tabular}{|r|r|r|}
\hline $\begin{array}{c}\text { Cronbach's } \\
\text { Alpha }\end{array}$ & $\begin{array}{c}\text { Cronbach's } \\
\text { Alpha Based on } \\
\text { Standardized } \\
\text { Items }\end{array}$ & N of Items \\
\hline .827 & .833 & \\
\hline
\end{tabular}

Summary Item Statistics

\begin{tabular}{|l|r|r|r|r|r|r|r|}
\hline & \multicolumn{1}{|c|}{ Mean } & Minimum & Maximum & \multicolumn{1}{l|}{ Range } & \multicolumn{1}{|l}{$\begin{array}{l}\text { Maximum / } \\
\text { Minimum }\end{array}$} & Variance & N of Items \\
\hline Item Means & 3.226 & 1.454 & 4.336 & 2.881 & 2.981 & .595 & 33 \\
Item Variances & 1.047 & .532 & 1.708 & 1.176 & 3.210 & .120 & 33 \\
\hline
\end{tabular}

\section{Scale Statistics}

\begin{tabular}{|c|c|c|c|}
\hline Mean & Variance & Std. Deviation & $\mathrm{N}$ of Items \\
\hline 106.46 & 174.821 & 13.222 & 33 \\
\hline
\end{tabular}


Item-Total Statistics

\begin{tabular}{|c|c|c|c|c|c|}
\hline & $\begin{array}{l}\text { Scale Mean if } \\
\text { Item Deleted }\end{array}$ & $\begin{array}{l}\text { Scale Variance } \\
\text { if Item Deleted }\end{array}$ & $\begin{array}{l}\text { Corrected } \\
\text { Item-Total } \\
\text { Correlation }\end{array}$ & $\begin{array}{l}\text { Squared } \\
\text { Multiple } \\
\text { Correlation }\end{array}$ & $\begin{array}{c}\text { Cronbach's Alpha if Item } \\
\text { Deleted }\end{array}$ \\
\hline a_5_1 & 104.32 & 164.667 & .283 & .286 & .825 \\
\hline a_5_2 & 104.43 & 184.579 & -.360 & .310 & .846 \\
\hline a_5_3 & 102.20 & 169.337 & .216 & .334 & .826 \\
\hline a_5_4 & 102.67 & 165.487 & .373 & .357 & .822 \\
\hline a_5_5 & 102.25 & 165.306 & .479 & .583 & .820 \\
\hline a_5_6 & 102.56 & 163.090 & .515 & .552 & .818 \\
\hline a_5_7 & 102.78 & 164.796 & .436 & .413 & .820 \\
\hline a_5_8 & 102.15 & 166.617 & .374 & .487 & .822 \\
\hline a_5_9 & 105.01 & 180.544 & -.274 & .327 & .839 \\
\hline a_5_10 & 102.49 & 163.911 & .456 & .528 & .819 \\
\hline a_5_11 & 102.13 & 169.083 & .273 & .435 & .825 \\
\hline a_5_12 & 103.21 & 163.860 & .373 & .407 & .821 \\
\hline a_5_13 & 103.05 & 163.779 & .452 & .366 & .819 \\
\hline a_5_14 & 103.27 & 167.867 & .170 & .256 & .829 \\
\hline a_5_15 & 103.43 & 163.899 & .363 & .409 & .822 \\
\hline a_5_16 & 103.53 & 164.121 & .327 & .484 & .823 \\
\hline a_5_17 & 104.01 & 163.163 & .390 & .484 & .821 \\
\hline a_5_18 & 103.79 & 181.604 & -.262 & .216 & .843 \\
\hline a_6_1 & 102.80 & 169.387 & .202 & .265 & .827 \\
\hline a_6_2 & 102.38 & 169.978 & .202 & .360 & .826 \\
\hline a_6_3 & 102.57 & 166.212 & .367 & .358 & .822 \\
\hline a_6_4 & 103.18 & 161.434 & .371 & .553 & .821 \\
\hline a_6_5 & 103.38 & 163.257 & .375 & .569 & .821 \\
\hline a_6_6 & 102.69 & 163.629 & .389 & .379 & .821 \\
\hline a_6_7 & 102.44 & 164.295 & .451 & .413 & .820 \\
\hline a_6_8 & 103.12 & 161.377 & .454 & .424 & .819 \\
\hline a_6_9 & 104.05 & 161.018 & .490 & .456 & .818 \\
\hline a_6_10 & 104.18 & 160.273 & .464 & .558 & .818 \\
\hline a_6_11 & 104.36 & 158.264 & .554 & .740 & .815 \\
\hline a_6_12 & 104.17 & 156.334 & .551 & .720 & .814 \\
\hline a_6_13 & 103.04 & 160.611 & .436 & .503 & .819 \\
\hline a_6_14 & 103.57 & 155.300 & .564 & .636 & .813 \\
\hline a_6_15 & 103.54 & 156.909 & .495 & .596 & .816 \\
\hline
\end{tabular}




\section{References}

Achrol, R. 1997. Changes in the theory of interorganizational relations in marketing: Toward a network paradigm. Journal of the Academy of Marketing Science, 25(1): 56-71.

Anderson, A. R., \& Jack, S. L. 2002. The articulation of social capital in entrepreneurial networks: A glue or a lubricant? Entrepreneurship \& Regional Development, 14(3): 193-210.

Anthony, S., Johnson M., and Sinfield, J., 2008. The Innovator's Guide to Growth. Harvard Business School Press.

Badaracco, J. 1991. The knowledge link: How firms compete throught strategic alliancesHarvard Business School Publishing India Pvt. Limited.

Baghai, M., Coley, S., \& White, D. 1999. The alchemy of growth: Practical insights for building the enduring enterprise. Reading, MA: Perseus Books.Carrelli, B.(2005, October), 2: 10-15.

Barney, J. B. 1991. Firm resources and sustained competitive advantage. Journal of Management, 17: 99-120.

Burt, R. S. 1997. The contingent value of social capital. Administrative Science Quarterly, 42(2): pp. 339-365.

Cohen, W. M., \& Levinthal, D. A. 19900301. Absorptive capacity: A new perspective on learning and innovation. Administrative Science Quarterly, 35(1).

Daum, J. H. Managing for sustained growth and profitability under rapid change and uncertainty: Insights from an intangibles-based view on enterprise and ecosystem management.

DeVellis, R. F. 2011. Scale development: Theory and applicationsSAGE Publications.

Fernandez, R. M., Castilla, E. J., \& Moore, P. 2000. Social capital at work: Networks and employment at a phone center. American Journal of Sociology, 105(5): pp. 1288-1356.

HÃkansson, H., \& Ford, D. 2002. How should companies interact in business networks? Journal of Business Research, 55(2): 133.

Hogan. J.E. 2001. Expected relationship value - A construct, a methodology for measurement, and a modeling technique. Industrial Marketing Management, 30(4): 339-351. 
Hogan, J.E., Armstrong, G. 2001. Toward a resource-based theory of business exchange relationships: the role of relational asset value. Journal of business-business marketing, $8(4): 3-26$

Kohtamäki, M., Partanen, J., \& Möller, K. 2013. Making a profit with R\&D services — the critical role of relational capital. Industrial Marketing Management, 42(1): 71.

Leiblein, M. J. 2011. What do resource-and capability-based theories propose? Journal of Management, 37(4): 909-932.

Mu, J., \& Di Benedetto, A. 2012. Networking capability and new product development. IEEE Transactions on Engineering Management, 59(1): 4.

Nahapiet, J., \& Ghoshal, S. 1998. Social capital, intellectual capital, and the organizational advantage. Academy of management review, 23(2): 242-266.

Nyaga, G. N., Whipple, J. M., \& Lynch, D. F. 2010. Examining supply chain relationships: Do buyer and supplier perspectives on collaborative relationships differ?. Journal of Operations Management, 28(2): 101.

Partanen, J., MÃller, K., Westerlund, M., Rajala, R., \& Rajala, A. 2008. Social capital in the growth of science-and-technology-based \SMEs\. Industrial Marketing Management, 37(5): 513.

Peteraf, M. A., \& Barney, J. B. 2003. Unraveling the resource-based tangle. Managerial and Decision Economics, 24(4): 309-323.

Pulles, N. J., \& Schiele, H. 2013 Back. Social capital determinants of preferential resource allocation in regional clusters. Management Revue, 24(2): 96.

Ritter, T., Wilkinson, I. F., \& Johnston, W. J. 2004. Managing in complex business networks. Industrial Marketing Management, 33(3): 175.

Svendsen, G. T., \& Svendsen, G. L. H. 2009. Ostrom, elinor, The Meaning of Social Capital and Its Link to collective action 2007. Handbook of social capital: The troika of sociology, political science and economicsEdward Elgar Publishing, Incorporated.

Teece, D. J. 2000. Strategies for managing knowledge assets: The role of firm structure and industrial context. Long range planning, 33(1): 35.

Tabachnick, B. G., \& Fidell, L. S. 2001. Using multivariate statistics. Allyn and Bacon.

Thorgren, S., Wincent, J., \& Örtqvist, D. 2012. Unleashing synergies in strategic networks of SMEs: The influence of partner fit on corporate entrepreneurship. International Small Business Journal, 30(5): 453. 
Ulaga, W., \& Eggert, A. 2005. Relationship value in business markets: The construct its dimensions. Journal of Business-to-Business Marketing, 12(1): 73.

Westerlund, M., \& Svahn, S. 2008. A relationship value perspective of social capital in networks of software \SMEs \. Industrial Marketing Management, 37(5): 492.

Wilson, D. T. 1995. An integrated model of buyer-seller relationships. Journal of the Academy of Marketing Science, 23(4): 335. 